\title{
Identification of Putative RuBisCo Activase (TaRca1)-The Catalytic Chaperone Regulating Carbon Assimilatory Pathway in Wheat (Triticum aestivum) under the Heat Stress
}

OPEN ACCESS

Edited by:

Puneet Singh Chauhan,

Council of Scientific and Industrial Research-National Botanical Research Institute, India

Reviewed by: Ankush Prasad,

Tohoku Institute of Technology, Japan Agata Gadaleta,

University of Bari, Italy

*Correspondence:

Ranjeet R. Kumar

ranjeetranjaniari@gmail.com

${ }^{\dagger}$ These authors have contributed equally to this work.

Specialty section: This article was submitted to Crop Science and Horticulture, a section of the journal Frontiers in Plant Science

Received: 14 May 2016 Accepted: 21 June 2016 Published: 12 July 2016

Citation:

Kumar RR, Goswami S, Singh K, Dubey $K$, Singh $S$, Sharma $R$, Verma N, Kala YK, Rai GK, Grover M, Mishra DC, Singh B, Pathak $H$, Chinnusamy V, Rai $A$ and Praveen $S$ (2016) Identification of Putative RuBisCo Activase (TaRca1) - The

Catalytic Chaperone Regulating

Carbon Assimilatory Pathway in Wheat (Triticum aestivum) under the Heat Stress. Front. Plant Sci. 7:986. doi: 10.3389/fpls.2016.00986
Ranjeet R. Kumar ${ }^{1+*}$, Suneha Goswami ${ }^{1+}$, Khushboo Singh ${ }^{1}$, Kavita Dubey ${ }^{1}$, Shweta Singh ${ }^{1}$, Renu Sharma ${ }^{1}$, Neeraj Verma ${ }^{1}$, Yugal K. Kala ${ }^{2}$, Gyanendra K. Rai ${ }^{3}$, Monendra Grover ${ }^{4}$, Dwijesh C. Mishra ${ }^{4}$, Bhupinder Singh ${ }^{5}$, Himanshu Pathak ${ }^{6}$, Viswanathan Chinnusamy ${ }^{7}$, Anil Rai ${ }^{4}$ and Shelly Praveen ${ }^{1}$

${ }^{1}$ Division of Biochemistry, Indian Agricultural Research Institute, New Delhi, India, ${ }^{2}$ Division of Genetics, Indian Agricultural Research Institute, New Delhi, India, ${ }^{3}$ School of Biotechnology, Sher-e-Kashmir University of Agricultural Sciences and Technology, Jammu, India, ${ }^{4}$ Centre for Agricultural Bioinformatics, Indian Council of Agricultural Research-Indian Agricultural Statistics Research Institute, New Delhi, India, ${ }^{5}$ Nuclear Research Laboratory, Plant Physiology, Indian Agricultural Research Institute, New Delhi, India, ${ }^{6}$ Center for Environment Science and Climate Resilient Agriculture, Indian Agricultural Research Institute, New Delhi, India, ${ }^{7}$ Division of Plant Physiology, Indian Council of Agricultural Research-Indian Agricultural Research Institute, New Delhi, India

RuBisCo activase (Rca) is a catalytic chaperone involved in modulating the activity of RuBisCo (key enzyme of photosynthetic pathway). Here, we identified eight novel transcripts from wheat through data mining predicted to be Rca and cloned a transcript of $1.4 \mathrm{~kb}$ from cv. HD2985, named as TaRca1 (GenBank acc. no. KC776912). Single copy number of TaRca1 was observed in wheat genome. Expression analysis in diverse wheat genotypes (HD2985, Halna, PBW621, and HD2329) showed very high relative expression of TaRca1 in Halna under control and HS-treated, as compared to other cultivars at different stages of growth. TaRca1 protein was predicted to be chloroplast-localized with numerous potential phosphorylation sites. Northern blot analysis showed maximum accumulation of TaRca1 transcript in thermotolerant $c v$. during mealy-ripe stage, as compared to thermosusceptible. Decrease in the photosynthetic parameters was observed in all the cultivars, except PBW621 in response to HS. We observed significant increase in the Rca activity in all the cultivars under HS at different stages of growth. HS causes decrease in the RuBisCo activity; maximum reduction was observed during pollination stage in thermosusceptible cvs. as validated through immunoblotting. We observed uniform carbon distribution in different tissues of thermotolerant cvs., as compared to thermosusceptible. Similarly, tolerance level of leaf was observed maximum in Halna having high Rca activity under HS. A positive correlation was observed between the transcript and activity of TaRca1 in HS-treated Halna. Similarly, TaRca1 enzyme 
showed positive correlation with the activity of RuBisCo. There is, however, need to manipulate the thermal stability of TaRca1 enzyme through protein engineering for sustaining the photosynthetic rate under HS - a novel approach toward development of "climate-smart" crop.

Keywords: RuBisCo activase, RuBisCo, photosynthesis, heat stress, wheat, IRGA, qRT-PCR, carbon partitioning

\section{INTRODUCTION}

Abiotic stresses, such as heat, drought, salinity, radiation, etc. are posing serious threat to agriculturally important crops and food security (Wang D. et al., 2010). Plants employ diverse defense mechanisms to overcome the deleterious effects of the stress and maintain growth and development (Zhu, 2001; Kumar et al., 2013). Heat stress (HS) is one of the major problems affecting the crop productivity (Bita and Gerats, 2013). Heat stress-mediated impairment of photosynthesis is one of the causes for reduction in yield of wheat. It causes an array of morphological, physiological, and biochemical changes such as reduction in the photosynthetic rate, disintegration of photosystem-II, membrane fluidization, denaturation of metabolic and defense related enzymes, drying of stigmatic surface, sterility of pollen, improper fertilization and seed-setting, shriveling of the grains, etc. (Kumar and Rai, 2014). Heat stress induces the expression of stress-associated genes (SAGs) coding for signaling proteins (CDPK, MAPK, etc.), heat shock proteins (low- and high-molecular weight), and antioxidant enzymes (SOD, CAT, POX, etc.) involved in imparting the thermotolerance of the crops (Kotak et al., 2007; Kumar et al., 2012).

Photosynthesis is highly heat-sensitive resulting in the considerable loss of productivity under HS (Wahid et al., 2007). Heat stress inactivates Ribulose-1, 5-bisphosphate carboxylase/oxygenase ( $\mathrm{RuBis} \mathrm{Co}$ ), the primary rate limiting enzyme of the carbon assimilatory process (Salvucci and Crafts-Brandner, 2004a).

RuBisCo constitute about 25\% of the leaf nitrogen and as much as $50 \%$ of soluble leaf protein (Parry et al., 2003). It is the key enzyme of carbon assimilatory pathway and exhibits maximum activity when all its active sites are in proper conformation. RuBisCo enzyme has L8S8 structure comprising eight large $(52 \mathrm{kDa})$ and eight small $(14-15 \mathrm{kDa})$ subunits (Andersson and Backlund, 2008). L8S8 structure of RuBisCo provides greater specificity for RuBP carboxylation than for its oxygenation activity (Jordan and Ogren, 1981). It binds to RuBP-derived enediol acceptor, before binding to the gaseous $\mathrm{CO}_{2}$ substrate (Cleland et al., 1998); besides, it has active-site with high affinity for transition-state intermediate, in which the incoming $\mathrm{CO}_{2}$ resembles a carboxylate group (Tcherkez et al., 2006). The stability of the RuBisCo enzymeintermediate complex is very high and it also causes strict binding of phosphate analogs (2-carboxy-D-arabinitol 1-phosphate, xylulose-1, 5-bisphosphate and D-glycero-2, 3-pentodiulose-1, 5-bisphosphate) causing low catalytic turnover of the RuBisCo (Kim and Portis, 2004). The binding of phosphate analogs and $\mathrm{RuBP}$ to the active site of RuBisCo is tight enough to inactivate the enzyme by locking the active site in a closed conformation (Salvucci and Crafts-Brandner, 2004b). The rate of deactivation of RuBisCo has been observed to increase with the increase in the temperature (Salvucci and Crafts-Brandner, 2004b). Several studies on cotton, tobacco, Arabidopsis, pea, and wheat have demonstrated that decreased photosynthetic rate during the leaf stress is due to the inactivation of RuBisCo (Law et al., 2001; Salvucci and Crafts-Brandner, 2004c). The closed conformation of the active site of $\mathrm{RuBisCo}$, due to unproductive binding of sugar phosphates, requires conformational remodeling by the RuBisCo activase (Portis, 2003). RuBisCo activase (Rca) is ATPases Associated with diverse cellular Activities (AAA+), which utilizes the energy from ATP to remodel the conformation by releasing the tightly-bound sugar phosphate, and restore its activity. Rca is a nuclear-encoded chloroplastic enzyme discovered by Salvucci et al. (1985) in higher plants. Rca is relatively abundant constituting about $5 \%$ of the soluble leaf protein (He et al., 1997). Under the optimal conditions, it removes the inhibiting sugar phosphates that block RuBisCo active sites, and restores RuBisCo to its fully functional state (Portis, 2003). Rca is highly heat-labile (Salvucci et al., 2001). RuBisCo deactivation occurs at temperatures above $30-32^{\circ} \mathrm{C}$, in most plants and at higher temperature $\left(>40^{\circ} \mathrm{C}\right)$, heat-induced loss of RuBisCo activity becomes irreversible (Kim and Portis, 2004). Some of the researchers reported that Rca under the favorable condition maintains the RuBisCo in its fully activated state, but it does not compensate for the high rate of RuBisCo deactivation during HS (Salvucci and Crafts-Brandner, 2004a), and as a result, the photosynthetic rate decreases, constraining the carbon assimilatory process.

Wheat, being heat-sensitive, is severely affected by HS, especially during flowering and grain-filling stages; HS drastically reduces the growth and yield, by disturbing the source-to-sink ratio and tolerance of the plant (Kumar et al., 2015). Very limited information is, however, available on Rca, its interaction with $\mathrm{RuBisCo}$, and correlation with photosynthetic rate and tolerance level in wheat (Triticum aestivum) under HS. The present study aimed at identification of RuBisCo activase gene(s) and elucidation of their role in the carbon assimilatory process of wheat under HS.

\section{MATERIALS AND METHODS}

\section{Plant Material and Stress Treatment}

Seeds of thermotolerant (HD2985 and Halna) and thermosusceptible (PBW621 and HD2329) wheat cvs. were procured from Division of Genetics, Indian Agricultural Research Institute (IARI), New Delhi. Seeds pre-treated with 
Bavistin @ 0.5\% were sown in pots (24 pots per cultivar) inside the climate regulated chamber with day/night temperature of $22 / 18^{\circ} \mathrm{C}$, RH of $75 \%$ and light intensity of $250 \mu \mathrm{mol}^{-2}$ $\mathrm{s}^{-1}$. Mixture of perlite, FYM and fine sand were used for the pot-filling. Pots were divided into two groups - one set for the control $\left(22 \pm 2^{\circ} \mathrm{C}\right)$ and another set for the HS treatment $\left(42^{\circ} \mathrm{C}, 2 \mathrm{~h}\right)$. Plants were exposed to HS inside microprocessor regulated chambers in a sinusoidal mode with an increment of $1^{\circ} \mathrm{C}$ for every $10 \mathrm{~min}$, till it reaches the HS-treated temperature. After HS, the temperature was, thereafter, lowered down to the ambient in the same fashion. Leaf samples were collected, in triplicates, from each stage of development (vegetative, anthesis, milky-ripe, and mealyripe) following the Feekes scale (Large, 1954), frozen in liquid nitrogen and stored at $-80^{\circ} \mathrm{C}$ for further downstream analysis. The work plan is presented in the supplementary file (Figure S1).

\section{RNA-Seq for the Identification of Novel Rca Transcripts}

De novo transcriptome analysis of control and HS-treated samples of wheat cvs. HD2985 and HD2329 were carried out using Illumina Hiseq 2000 to identify heat-responsive genes (BioProject accession no. PRJNA171754). The unigenes were annotated using different databases and the transcript sequences coding for protein with RuBisCo activase-specific domain were mined from the data; we found 10 different transcripts with AAA+ ATPase conserved domain. All the predicted Rca transcripts were aligned using ClustalW alignment tool and we observed that eight of the transcripts have more than $88 \%$ similarities among them, whereas two of the transcripts showed very low similarity with others. These transcripts which showed low similarity from others were targeted for the cloning and characterization.

\section{Molecular Cloning of Rca Gene Transcript-Specific Oligo's Designing}

The transcripts predicted to be $R c a$ were used for the primer designing using Prime Perfect Tool (Invitrogen, UK) applying all the default parameters and the primers were subjected to quality check using OligoCalc (http://www. basic.northwestern.edu/biotools/oligocalc.html); HPLC-purified oligo's were synthesized commercially (Table S1).

\section{Isolation of Total RNA and cDNA Synthesis}

Total RNA was isolated from the control and HS-treated leaf samples of wheat $c v$. HD2985 by the Trizol method (Invitrogen, UK) and the quality was checked using Bioanalyzer (Agilent, UK); RNA samples with OD 260/280 ratio of more than 2.0 was used for the cDNA synthesis. The integrity of isolated RNA was also checked on $1.2 \%$ agarose gel. cDNA was synthesized using the RevertAid ${ }^{\mathrm{TM}} \mathrm{H}$ minus First Strand cDNA synthesis kit (Thermo fisher Scientific, USA), following the manufacturers protocol and its quality was checked with Qubit $^{\mathrm{TM}}$ 2.0 Fluorometer (Invitrogen, UK).

\section{Cloning and Reverse Transcriptase-PCR (RT-PCR) Analysis of Rca}

The transcript-specific oligo's were used for the RT-PCR amplification using the cDNA templates of the control and HStreated samples with $2 \mathrm{x}$ PCR master mix (Promega, Madison, UK). The PCR cycle followed was $98^{\circ} \mathrm{C}$ for $4 \mathrm{~min}$, followed by 35 cycles of $94^{\circ} \mathrm{C}$ for $30 \mathrm{~s}, 58^{\circ} \mathrm{C}$ for $45 \mathrm{~s}$, and $72^{\circ} \mathrm{C}$ for $1 \mathrm{~min}$. Further, treatment of $72^{\circ}$ for $10 \mathrm{~min}$ was given for the stabilization, followed by hold at $4{ }^{\circ} \mathrm{C}$. The amplified product was loaded on to $1 \%$ agarose gel and an amplicon of $\sim 1.4 \mathrm{~kb}$ was observed; the product was eluted from the gel and cleaned with PCR clean-up kit (Promega, Madison, UK); the eluted product was cloned in pGEM-T Easy vector (Promega, Madison, UK) and transformed in E. coli strain $\mathrm{DH} 5 \alpha$ competent cells, following the standard protocol (Sambrook et al., 1989). The cloned gene was subjected to restriction analysis, and sequenced using Sanger's di-deoxy method using T7 and SP6 primers.

\section{In silico Characterization of the Cloned TaRca1}

The cloned TaRcal gene was characterized for its homology by using BLASTn tool of National Center for Biotechnology Information (NCBI; https://blast.ncbi.nlm.nih.gov/). The nucleotide sequence was submitted to GenBank (http://www. ncbi.nlm.nih.gov/genbank/). Translated sequence of the cloned TaRcal gene was predicted using Expasy tool (http://expasy. org/tools/); open reading frame (ORF) was predicted using ORF Finder (http://www.ncbi.nlm.nih.gov/projects/gorf/). The conserved domain (CD) of the gene was searched with $\mathrm{CD}$ search tool of NCBI (http://www.ncbi.nlm.nih.gov/Structure/ cdd/wrpsb.cgi).

\section{Southern Blot Analysis to Know the Copy Number of Cloned TaRca1 Gene}

Southern blot analysis was carried out in thermotolerant wheat cv. HD2985. Genomic DNA was isolated from the etiolated seedlings of $c v$. HD2985 by cetyl-trimethylammonium bromide (CTAB) method (Procunier et al., 1990). Twelve microgram of genomic DNA was digested with the restriction endonucleases EcoRI, HinDIII, and BamHI (HF restriction enzyme, NEB, UK) overnight at $37^{\circ} \mathrm{C}$ and resolved on $0.8 \%$ agarose gel $(15 \mathrm{~V}$ for $12 \mathrm{~h})$. The resolved DNA was blotted onto a piece of nylon membrane (Hybond- $\mathrm{N}^{+}$, Amersham Biosciences, Uppsala, Sweden) using iBlot ${ }^{\mathrm{TM}}$ (Invitrogen, UK). DNA on the blot was denatured with an alkaline buffer $(0.5 \mathrm{~N} \mathrm{NaOH}, 1.5 \mathrm{M}$ $\mathrm{NaCl})$ for $2 \mathrm{~min}$, soaked in a neutralizing buffer $(0.5 \mathrm{M}$ Tris $\mathrm{HCl}$ [pH 7.5], $1.5 \mathrm{M} \mathrm{NaCl}$ ) for $2 \mathrm{~min}$ the membrane was baked at $80^{\circ} \mathrm{C}$ for $1 \mathrm{~h}$. The baked membrane was pre-hybridized in a prehybridization buffer [0.5\% sodium dodecyl sulfate (SDS), 6 X SSC, $5 \mathrm{X}$ denhardt's solution] containing $100 \mu \mathrm{g}$ of salmon sperm DNA (Pharmacia, Uppsala, Sweden) per $\mathrm{ml}$ at $65^{\circ} \mathrm{C}$ for $4 \mathrm{~h}$. The probe (TaRcal fragment of $\sim 600$ bp generated after the restriction of the gene) was labeled with biotin labeling mix (Fermentas, UK) and was used for the hybridization of the membrane at $65^{\circ} \mathrm{C}$ for $15 \mathrm{~h}$ inside the Hybridizer. The hybridized membrane was washed twice with $0.1 \%$ SDS in $2 \times$ SSC $(150 \mathrm{mmol} / \mathrm{L}$ 
$\mathrm{NaCl}, 15 \mathrm{mmol} / \mathrm{L}$ sodium citrate) solution for $10 \mathrm{~min}$ at room temperature, and then twice with $0.1 \%$ SDS in $0.2 \times$ SSC solution for $20 \mathrm{~min}$ at $65^{\circ} \mathrm{C}$. Biotin-labeled probe-target hybrids were detected with alkaline phosphatase-conjugated streptavidin using the Biotin Chromogenic Detection kit (Thermo fisher Scientific, USA). The blot developed was immediately washed in water and the image was captured using Gel Doc Easy (Bio Rad, UK).

\section{Northern Blot Analysis}

Expression analysis of cloned TaRcal gene was carried out in contrasting wheat cvs. HD2985 (thermotolerant) and H2329 (thermosusceptible) by using northern blotting. Total RNA was isolated from the collected samples by the Trizol method (Invitrogen, UK) and quantified with Qubit ${ }^{\mathrm{TM}} 2.0$ Fluorometer (Invitrogen, UK); the integrity was verified on $1.2 \%$ agarose gel. For northern blot analysis, $6 \mu \mathrm{g}$ of total RNA was loaded onto $1.2 \%$ formaldehyde agarose gel, and run at $45 \mathrm{~V}$ for $2 \mathrm{~h}$. The resolved RNA was blotted on to Nylon membrane using iBlotter (Invitrogen, UK). The membrane was UV-cross linked and baked at $80^{\circ} \mathrm{C}$ for $1 \mathrm{~h}$. Further, the membrane was pre-hybridized in a hybridization buffer ( $1 \%$ SDS, $1.5 \mathrm{M} \mathrm{NaCl}, 10 \%$ dextran sulfate) containing $100 \mu \mathrm{g}$ of salmon sperm DNA (Pharmacia, Uppsala, Sweden) per $\mathrm{mL}$ at $65^{\circ} \mathrm{C}$ for $4 \mathrm{~h}$. RuBisCo activase (TaRca1) DNA was labeled with $\alpha-\left[{ }^{32} \mathrm{P}\right]$-dCTP (BRIT, Bhabha Atomic Research Centre, India) and was used as a probe for the hybridization at $65^{\circ} \mathrm{C}$ for $15 \mathrm{~h}$. The membrane was washed twice with $0.1 \%$ SDS in $2 \times \mathrm{SSC}(150 \mathrm{mmol} / \mathrm{L} \mathrm{NaCl}, 15 \mathrm{mmol} / \mathrm{L}$ sodium citrate) solution for $15 \mathrm{~min}$, and then twice with $0.1 \%$ SDS in $0.2 \times$ SSC solution for $15 \mathrm{~min}$ at $50^{\circ} \mathrm{C}$. An X-ray film was exposed to the air-dried radio-labeled membrane, and the signals were quantified using automatic $\mathrm{x}$-ray developer.

\section{Expression Analysis of Tarca1 Using Quantitative Real-Time PCR (qRT-PCR)}

Total RNA was isolated from the control and HS-treated samples of wheat cvs. HD2985, HD2329, Halna, and PBW621 by the Trizol method (Invitrogen, UK) and was quantified using Qubit ${ }^{\mathrm{TM}}$ 2.0 Fluorometer (Invitrogen, UK). First strand cDNA synthesis was performed, using oligo dT primers and the Superscript II reverse transcriptase (Invitrogen, UK) according to the manufacturer's instructions. First-strand cDNA was diluted to a final concentration of $100 \mathrm{ng} / \mu \mathrm{L}$ and real-time PCR was carried out as described earlier (Kumar et al., 2013). Expression analysis was carried out in three biological and three technical replicates. The expression levels of wheat $\beta$-actin gene (accession no. AF282624) was used for normalizing the $C t$-value. The comparative $C_{t}\left(2^{-\Delta \Delta C t}\right)$ method was used to calculate the relative expression of the TaRcal (Pfaffl et al., 2002).

\section{Photosynthetic Rate and Stomatal Conductance Analysis}

The wheat cvs. HD2985, HD2329, PBW621, and Halna under control $\left(22 \pm 3^{\circ} \mathrm{C}\right)$ and $\mathrm{HS}\left(38^{\circ} \mathrm{C}, 2 \mathrm{~h}\right)$ during the grain-filling (Feekes-11.1) stage were subjected to infra-red gas analyzer (IRGA) for analyzing the effect of HS on the photosynthesis (LiCor 6400, LiCor Inc., USA), and the observations were recorded following Long and Bernacchi (2003). Fully expanded flag leaf was used for the IRGA analysis, and the readings were taken in triplicates between 11 a.m. and 12 p.m. Photosynthesis was measured at constant saturating light of $1500 \mu \mathrm{mol} \mathrm{m}^{-2} \mathrm{~s}^{-1}$. Measurements of leaf $\mathrm{R}_{\text {dark }}$ were made on dark-adapted leaves after 30 min of dark adaptation to achieve steady-state $R_{\text {dark }}$.

\section{RuBisCo Activity Assay}

The leaf samples collected from the wheat $c v s$. HD2985, HD2329, PBW621, and Halna (control and HS-treated) during anthesis, milky-ripe, and mealy-ripe stages were used for the activity assay. One gram leaf was crushed into fine powder using liquid nitrogen in $5 \mathrm{~mL}$ extraction buffer [50 mM Tris- $\mathrm{HCl}$ (pH 8.0), $1 \mathrm{mM}$ EDTA, $1 \mathrm{mM}$ PMSF, $0.1 \%$ BSA]. The extract was centrifuged at $9000 \mathrm{~g}$ for $15 \mathrm{~min}$ and the supernatant was decanted into separate tubes. One milliliter supernatant was activated by incubating at RT in the activation buffer $[0.1 \mathrm{~mL}$ each of $10 \mathrm{mM} \mathrm{NaHCO} 3,10 \mathrm{mM} \mathrm{MgCl}_{2}, 5 \mathrm{mM}$ glutathione, $0.1 \mathrm{mM}$ EDTA, and $0.6 \mathrm{~mL}$ Tris- $\mathrm{HCl}(50 \mathrm{mM}) \mathrm{pH} 8.0]$. Reaction mixture was prepared by adding $0.2 \mathrm{~mL}$ Tris- $\mathrm{HCl}(\mathrm{pH} 8.0), 0.1 \mathrm{~mL}$ labeled $\mathrm{NaH}^{14} \mathrm{CO}_{3}\left(20 \mathrm{mM}\right.$, specific activity $50 \mathrm{mCi} \mathrm{mmol}{ }^{-1}$, BARC, Mumbai), and $0.1 \mathrm{~mL}$ unlabeled $\mathrm{NaHCO}_{3}, 0.01 \mathrm{ml} \mathrm{MgCl}$ (3.03 $\mu \mathrm{mole}), 0.01 \mathrm{ml}$ EDTA, $0.1 \mathrm{~mL}$ activated enzyme extract, and $0.1 \mathrm{~mL}$ RuBP $(0.2 \mu$ mole). The reaction was started by addition of RuBP and terminated after 120 min with addition of $0.2 \mathrm{~mL} 6 \mathrm{~N}$ acetic acid. The contents were evaporated to dryness at $65^{\circ} \mathrm{C}$ and the acid stable ${ }^{14} \mathrm{C}$ was counted using liquid scintillation counter (Packard, Tri-Carb, 1600 TR USA). Assay medium without RuBP served as blank for each assay.

\section{Immunoblot Assay of RuBisCo}

The control and HS-treated leaf samples collected from wheat cvs. HD2985 and HD2329 during the vegetative, pollination, and grain-filling were subjected to western blot analysis described earlier (Kumar et al., 2013). The dilution used for the incubation of membrane in primary monoclonal antibody (anti-RuBisCo) and secondary antibody (peroxidase-conjugated goat anti-mouse IgG) was 1:1000. Band of desired intensity was visible after 2-5 min incubation, and the membrane was washed immediately in water, and Tris-buffered saline (TBS). The dried membrane was used for photography with Gel Doc Easy (Bio Rad, UK).

\section{RuBisCo Activase Activity Assay}

Rca activity was estimated in control and HS-treated leaf samples of wheat cvs. HD2985, HD2329, PBW621, and Halna collected at pollination, milky-ripe, and mealy-ripe stages. Fresh leaf $(0.3 \mathrm{~g})$ was crushed in $600 \mu \mathrm{L}$ of extraction buffer $[50 \mathrm{mM}$ Tricine buffer (pH-7), $100 \mathrm{mM} \mathrm{MgCl} 2,10 \mathrm{mM} \mathrm{NaHCO} 3,1 \mathrm{mM}$ EDTA, 1 mM ATP, 10 mM DTT, 1 mM PMSF, 2 mM Benzamide, $0.01 \mathrm{mM}$ Leupeptin] and centrifuged at 13,000 rpm for $20 \mathrm{~min}$. The supernatant collected was used for the protein estimation by Bradford method (Bradford, 1976). For the activity assay of Rca, $40 \mu \mathrm{g}$ of extract was taken along with denatured crude extract (incubated at $65^{\circ} \mathrm{C}$ for $10 \mathrm{~min}$ ) and $25 \mu \mathrm{L}$ of assay medium [100 mM Tricine buffer (pH-8), $10 \mathrm{mM} \mathrm{MgCl}_{2}, 10 \mathrm{mM}$ $\mathrm{NaHCO}_{3}$, 1 mM ATP, 4 mM RuBP, 1 mM Phosphoenolpyruvate, Pyruvate kinase $(20 \mathrm{U} / \mathrm{ml})]$ and $25 \mu \mathrm{L}$ of RuBP-RuBisCo complex 
(1 mg RuBP and $1 \mathrm{mg}$ RuBisCo was taken and dissolve in $1.5 \mathrm{~mL}$ of water, and kept at $40^{\circ} \mathrm{C}$ for $30 \mathrm{~min}$ ) was added in both the scintillation vials. The reaction was allowed for $30 \mathrm{~s}$, and further, $450 \mu \mathrm{L}$ of radio-labeled assay mix [100 mM Tricine buffer ( $\mathrm{pH}-8$ ), $10 \mathrm{mM} \mathrm{MgCl}_{2}, 0.5 \mathrm{mM} \mathrm{RuBP}, 20 \mathrm{mM}$ $\mathrm{NaH}^{14} \mathrm{CO}_{3}$ (specific activity $50 \mathrm{mCi} \mathrm{mmol}{ }^{-1}, \mathrm{BARC}$ Mumbai)] was added. The reaction was terminated by adding $100 \mu \mathrm{L}$ of $1 \mathrm{~N} \mathrm{HCl}$. The contents of the vials were evaporated to dryness at $65^{\circ} \mathrm{C}$ and the acid stable ${ }^{14} \mathrm{C}$ was subsequently counted in the liquid scintillation counter (Packard, Tri-Carb, 1600 TR USA). The RCA activity was calculated by comparing the disintegration per minute (DPM) of samples (controldenatured) and $\mathrm{NaH}^{14} \mathrm{CO}_{3}$.

\section{Estimation of Reducing, Non-reducing, and Total Sugars}

The samples (control and HS-treated) collected from wheat cvs. HD2985, HD2329, PBW621, and Halna during grain-filling (milky-ripe and mealy-ripe) stage were used for the estimation of reducing, non-reducing, and total sugars. Reducing sugars from the fresh leaves and stems were estimated by the 3, 5dinitrosalicylic acid (DNS) method (Miller, 1959). Fresh samples $(0.1 \mathrm{~g})$ were homogenized in $80 \%$ ethanol and centrifuged at 5000 $\mathrm{g}$ for $15 \mathrm{~min}$ at the room temperature; the supernatant was used for the sugars estimation using the standard of glucose. Nonreducing sugar was estimated by acid hydrolysis of the samples in sulfuric acid. Total sugar was estimated by phenol sulfuric acid method (Dubois et al., 1956).

\section{Estimation of Total Antioxidant Capacity (TAC)}

Leaves of control and HS-treated samples collected from all the four cultivars at pollination, milky-ripe, and mealy-ripe stages were used for the TAC estimation. TAC was assayed in the fresh leaves as described by Benzie and Strain (1999). The antioxidant capacity was expressed as ferric-reducing ability of $1 \mathrm{mmol} / \mathrm{L}$ $\mathrm{FeSO}_{4}$.

\section{RESULTS}

\section{Identification of Transcripts Predicted to be RuBisCo Activase (Rca)}

The data generated from the de novo whole-transcriptome sequencing of wheat cvs. HD2985 and HD2329 (BioProject accession no. PRJNA171754) were mined for the prediction of transcripts coding for Rca. Mining of the RNA-seq data revealed the presence of eight putative Rca transcripts based on the domain search (presence of Rca-specific ATPases Associated with diverse cellular Activities superfamily of ring-shaped Ploop NTPases domain; Table S2). The transcript sequence of identified putative Rca genes is presented in the supplementary file (Table S3). Based on the in silico characterization and size of the transcripts, we targeted transcript_5 for the cloning and characterization.

\section{Cloning and In silico Characterization of Putative Rca}

An amplicon of $\sim 1.4 \mathrm{~kb}$ was amplified from wheat $c v$. HD2985 using transcript specific primers. The amplified product was purified and cloned in pGEM-T Easy vector. Sanger's sequencing using di-deoxy method showed the presence of 1402 nucleotides with an open reading frame of 432 aa starting from 23 to $1321 \mathrm{nt}$. Based on the homology search, the gene was named as TaRcal. The nucleotide sequence was submitted in NCBI (GenBank accession no. KC776912).

BLASTn search showed maximum homology with RcaB reported from Triticum (acc. no. AF251264.1) and cDNA clone (FLbaf169e16) from Hordeum vulgare (acc. no. AK252703.1). Protein-based homology search, using BLASTp suite of NCBI, showed maximum (99\%) homology with Rca protein reported from Triticum urartu (acc. no. EMS57011.1) followed by 93\% with $R c a B$ reported from Aegilops tauschii (acc. no. EMT06779.1).

TaRcal protein was predicted to be chloroplast-localized. We observed numerous potential phosphorylation sites with serine, threonine, and tyrosine residues in the TaRcal protein; four sites with tyrosine and two sites with serine and threonine were predicted to have phosphorylating potential above the threshold. Based on the phosphorylating sites, the maximum kinase activity was predicted for the Protein kinase C (PKC) - a family of serine/threonine protein kinase enzymes. A prominent domain was observed between the region $121-354$ aa predicted to belong to superfamily P-loop containing nucleoside triphosphate hydrolases and family AAA-ATPase domain.

Based on the phylogeny tree, the Rca was classified into four different sub-families with TaRcal lying under subfamily-I (Figure 1A). The cloned TaRcal was subjected to phylogeny analysis along with RuBisCo activase reported from Zea mays (Figure 1B). Based on the amino acid sequence analysis, the RuBisCo activase was broadly classified into two families(a) Family-I and (b) Family-II, with family-II having three subfamilies; cloned TaRcal was observed in subfamily-II of family-I. Similarly, Rca reported from Oryza sativa was used for the phylogeny analysis along with Rca reported from wheat (Figure 1C). Rca was classified into two families with family-II having four different subfamilies; cloned TaRcal was observed in subfamily-II.

\section{Southern and Northern Blot Analysis of TaRca1 Gene}

To find out the copy number of the cloned TaRcal gene from wheat, southern blot analysis was carried out using the genomic DNA isolated from wheat $c v$. HD2985. We observed single prominent blot in each lane (restricted with EcoRI, HinDIII, and BamHI; Figure 2). EcoRI restricted lane showed band of $\sim 3.2 \mathrm{~kb}$, whereas BamHI and HinDIII showed bands of $\sim 2.8$ and $\sim 4.0 \mathrm{~kb}$. This result suggests that cloned TaRcal has single copy in Triticum aestivum.

The expression of cloned TaRcal was further analyzed though northern blotting in the contrasting wheat cvs. HD2985 and HD2329 under control and HS-treated conditions. We observed 


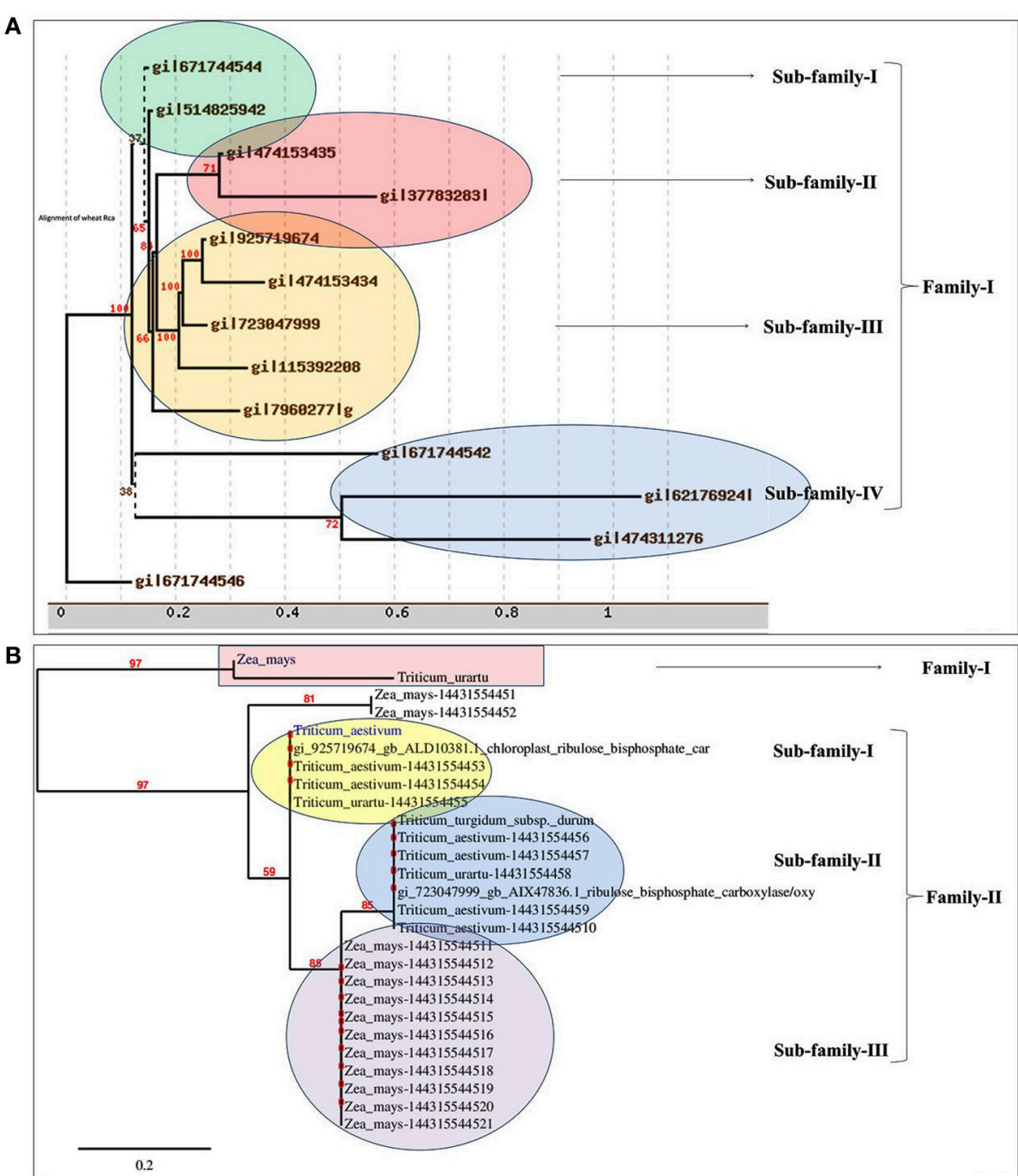

C

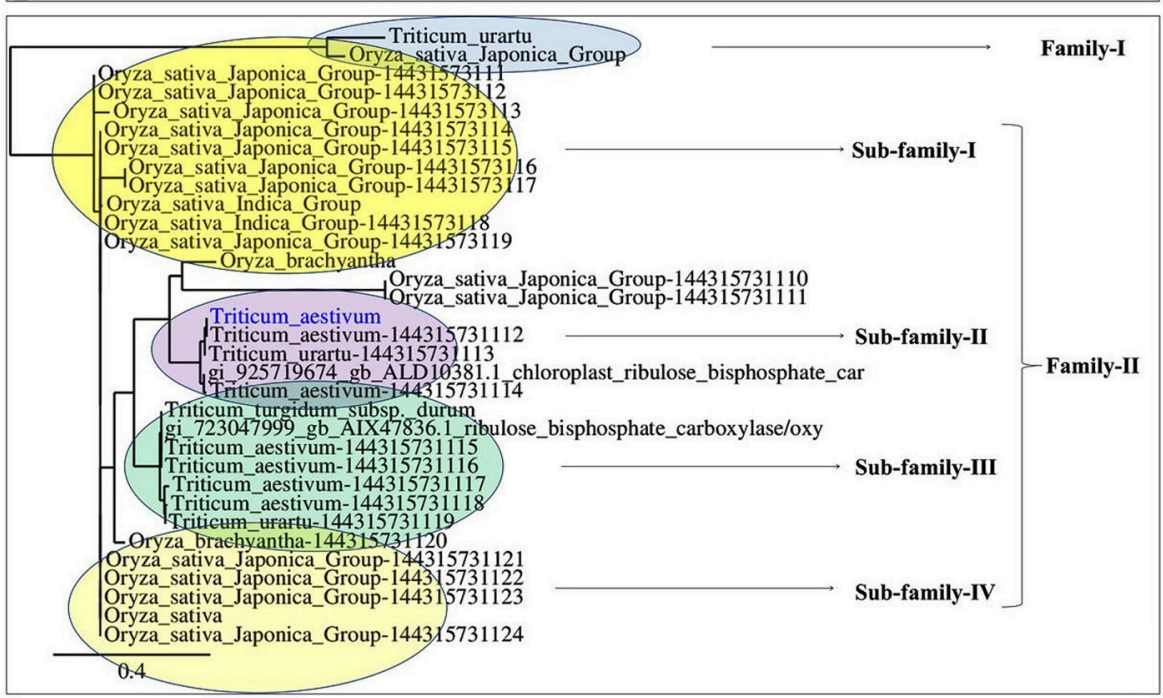

FIGURE 1 | Phylogenetic analysis of RuBisCo activase gene (TaRca1) cloned from wheat cv. HD2985. (A) Classification of TaRca1 based on RuBisCo activase reported from other plant and non-plant sources, (B) Classification based on Rca reported from Zea mays; (C) Classification based on Rca reported from Oryza sativa. 


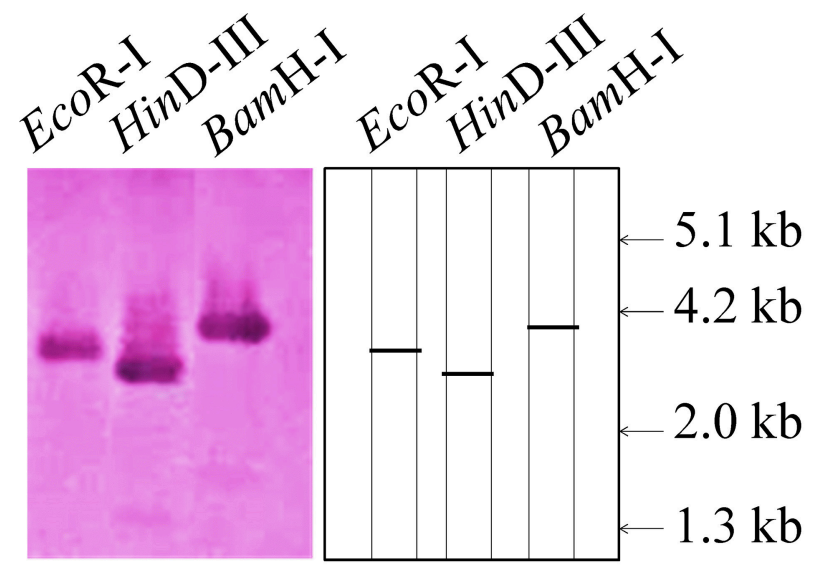

FIGURE 2 | Southern blot analysis to identify the copy number of cloned RuBisCo activase (TaRca1) gene from wheat cv. HD2985; EcoRI, HinDIII, and BamHI enzymes were used for the restriction; $12 \mu \mathrm{g}$ genomic DNA was used per sample; $0.8 \%$ agarose gel was used for the electrophoretic separation of restricted product; Biotin-labeled probe was used for the hybridization.

significant increase in the expression of TaRcal transcripts in HD2985 under HS, as compared with the control at all the stages studied; most prominent accumulation of transcript was observed during grain-filling (mealy-ripe) stage under HS (Figure 3). Similar pattern of expression was observed in cv. HD2329; the expression levels of TaRcal under HS was, however, lower in HD2329 (thermosensitive) than in HD2985 (thermotolerant).

\section{Alterations in the Photosynthesis-Associated Parameters under HS}

We observed significant decrease in the photosynthetic rate in response to HS in HD2985, HD2329, and Halna except PBW621. Decrease in the photosynthetic rate was maximum in Halna and HD2985 (Figure 4). Stomatal conductance also decreased due to HS, in all the cultivars except PBW621; decrease was maximum in HD2985. Significant decrease in the intracellular $\mathrm{CO}_{2}$ was observed in response to $\mathrm{HS}$ in all the cultivars; differences were, however non-significant in PBW621. Similarly, transpiration rate also decreased due to HS in all the cultivars except PBW621, the decrease being highest in HD2985.

\section{Expression Pattern of TaRca1 in Different Wheat Genotypes under Heat Stress}

HD2329 showed very high relative expression of TaRcal in response to HS, as compared to control during pollination and grain-filling stages; maximum expression was observed during grain-filling in response to HS (Figure 5A). Similar pattern of expression of TaRcal was observed in PBW621, HD2985, and Halna under control and HS-treated conditions (Figures 5B-D). Of all the cvs., relative expression of TaRcal under HS was observed maximum in Halna and minimum in HD2329 during

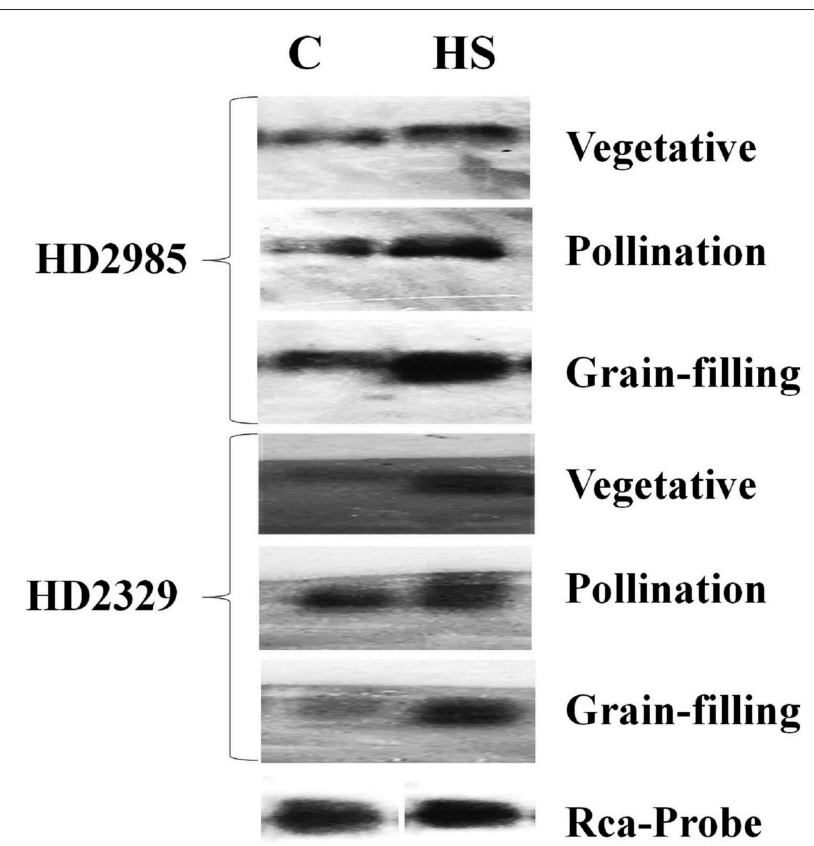

FIGURE 3 | Northern blot analysis of cloned RuBisCo activase (TaRca1) gene in contrasting wheat cvs. HD2985 and HD2329 at different stages of growth and development; [ $\left.\alpha{ }^{32} \mathrm{P}\right]-\mathrm{dCTP}(300 \mu \mathrm{Ci})$ were used for the probe labeling; $1.2 \%$ agarose gel was used for the electrophoretic separation of total RNA.

both the stages of growth. In general, abundance of TaRcal transcript was observed during the grain-filling in all the four cultivars in response to HS.

\section{Changes in the Rca Activity under Heat Stress}

HD2985 showed maximum Rca activity during mealy-ripe stage, both under control $\left(0.54 \mu\right.$ mole $\mathrm{CO}_{2} / \mathrm{min} / \mathrm{mg}$ protein $)$ and HS-treated $\left(1.19 \mu\right.$ mole $\mathrm{CO}_{2} / \mathrm{min} / \mathrm{mg}$ protein) conditions (Figure 6A). We observed significant increase in the Rca activity in HD2985 under HS at different stages of development.

In case of HD2329, we observed maximum Rca activity during milky-ripe stage in response to $\mathrm{HS}$, and mealy-ripe stage under control condition (Figure 6B). Non-significant difference in the Rca activity in HD2329 under HS was observed during milky- and mealy-ripe stages. Similar pattern of Rca activity was observed in Halna under control and HStreated conditions at all the stages of development. Halna showed maximum Rca activity during mealy-ripe stage under control $\left(0.62 \mu\right.$ mole $\mathrm{CO}_{2} / \mathrm{min} / \mathrm{mg}$ protein) and HS-treated (1.22 $\mu$ mole $\mathrm{CO}_{2} / \mathrm{min} / \mathrm{mg}$ protein) conditions (Figure 6C). PBW621 showed non-significant difference in the Rca, as observed in HS-treated samples collected during different stages of development. Maximum Rca activity was observed during mealy-ripe stage, both under control $\left(0.69 \mu\right.$ mole $\mathrm{CO}_{2} / \mathrm{min} / \mathrm{mg}$ protein) and HS-treated $\left(0.94 \mu\right.$ mole $\mathrm{CO}_{2} / \mathrm{min} / \mathrm{mg}$ protein $)$ conditions (Figure 6D). 

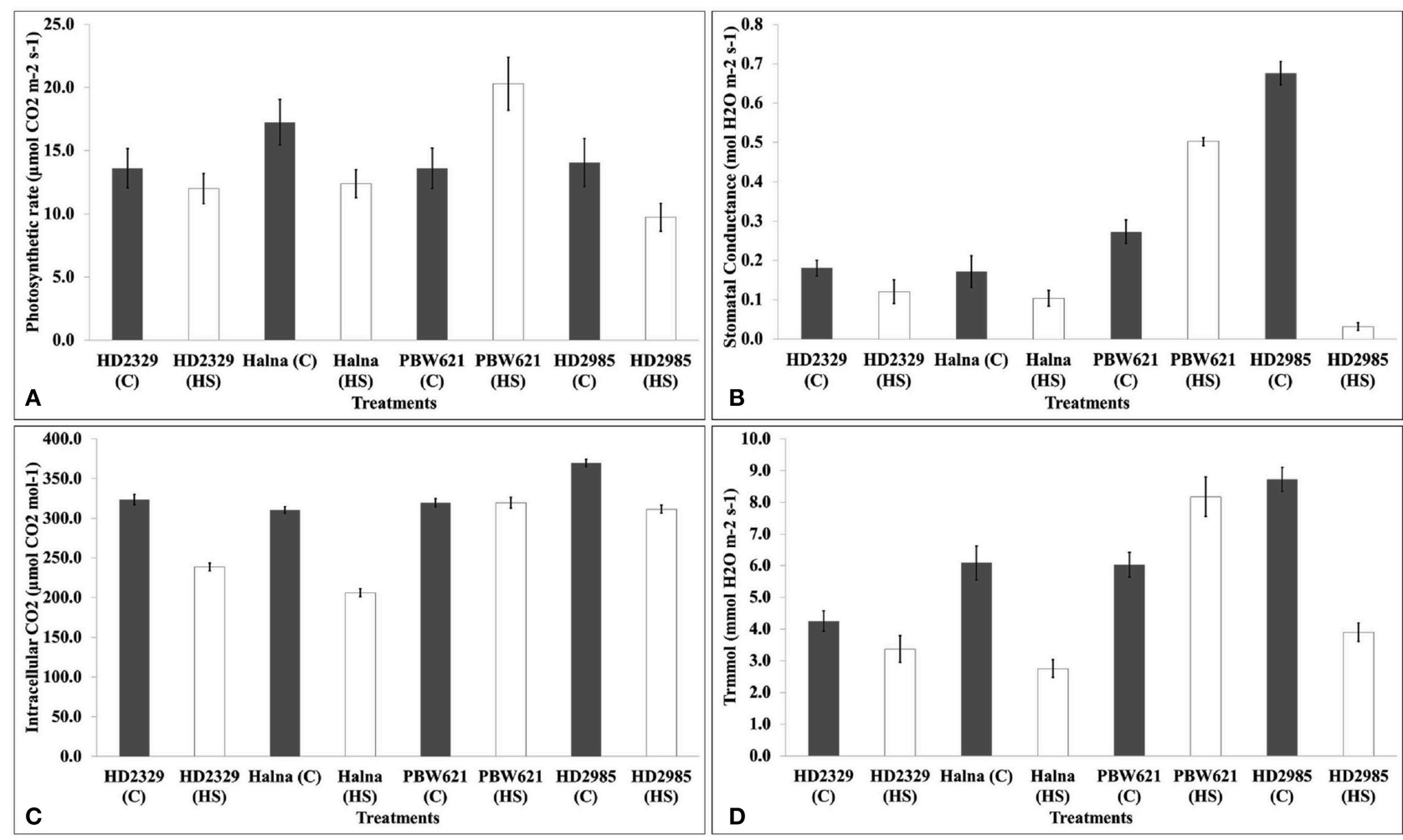

FIGURE 4 | Infra-Red Gas Analyzer (IRGA) analysis of full expanded leaves of different wheat cvs. under control and heat stress conditions. (A) Photosynthetic rate, (B) Stomatal conductance, (C) Intracellular carbon dioxide, (D) Transpiration rate; $\mathrm{C}-22 \pm 3^{\circ}$, heat stress $-42^{\circ} \mathrm{C}$ for $2 \mathrm{~h}$; Leaves of HD2985, HD2329, Halna and PBW621 were used for the analysis; vertical bars indicate SE $(n=3)$.

\section{Changes in the RuBisCo Activity under Heat Stress}

HD2985 showed maximum RuBisCo activity during mealy-ripe stage, both under control ( 4.3 nmole $\mathrm{CO}_{2} / \mathrm{min} / \mathrm{mg}$ protein) and HS-treated $\left(2.69 \mathrm{nmole} \mathrm{CO}_{2} / \mathrm{min} / \mathrm{mg}\right.$ protein) conditions (Figure 7A). HS causes decrease in the RuBisCo activity; maximum reduction was observed during pollination stage. In case of HD2329, we observed maximum RuBisCo activity during milky-ripe stage $\left(6.5 \mathrm{nmole} \mathrm{CO}_{2} / \mathrm{min} / \mathrm{mg}\right.$ protein $)$ under control condition and mealy-ripe stage ( 4 nmole $\mathrm{CO}_{2} / \mathrm{min} / \mathrm{mg}$ protein) under HS-treated condition (Figure $7 \mathbf{B}$ ). Percent reduction in RuBisCo activity in HD2329 under HS was observed maximum during milky-ripe stage, as compared to other stages of development. Halna showed non-significant differences in the RuBisCo activity estimated in control and HS-treated samples at different stages of development (Figure 7C). PBW621 showed similar pattern of RuBisCo activity as shown by HD2985 under control and HS-treated conditions. Maximum RuBisCo activity was observed during mealy-ripe stage, both under control (5.3 nmole $\mathrm{CO}_{2} / \mathrm{min} / \mathrm{mg}$ protein) and HS-treated ( $3.5 \mathrm{nmole}$ $\mathrm{CO}_{2} / \mathrm{min} / \mathrm{mg}$ protein) conditions (Figure 7D). Overall, RuBisCO activity was observed maximum in HD2329, both under control and HS-treated conditions at different stages of growth.

\section{Accumulation Pattern of RuBisCo Protein under HS}

In HD2329, we observed decrease in the intensity of the RuBisCo (Large Subunit) band in response to HS, as compared with the control, at vegetative, pollination, and grain-filling stages; the decrease was more prominent in HS-treated samples at the vegetative stage (Figure 8A). Maximum accumulation of RuBisCo (LSU) was in HD2329 during the pollination stage. In HD2985, the effect of HS on accumulation of RuBisCo (LSU) was not prominent at different stages of growth and only slight decrease in the band intensity was observed under HS (Figure 8B).

Stage-specific RuBisCo accumulation-pattern was also studied in the wheat cultivars during all the stages mentioned above. Prominent accumulation of RuBisCo was observed during the milky-ripe and mealy-ripe sub-stages in HD2985 (Figure 8C), whereas in HD2329, maximum accumulation was observed during the pollination and milky-ripe stage, which decreased thereafter (Figure 8D).

\section{Pattern of Sugars Accumulation in Stems and Leaves under HS}

RuBisCo and Rca directly influence the synthesis and distribution of reducing and non-reducing sugars in the leaves (source), 


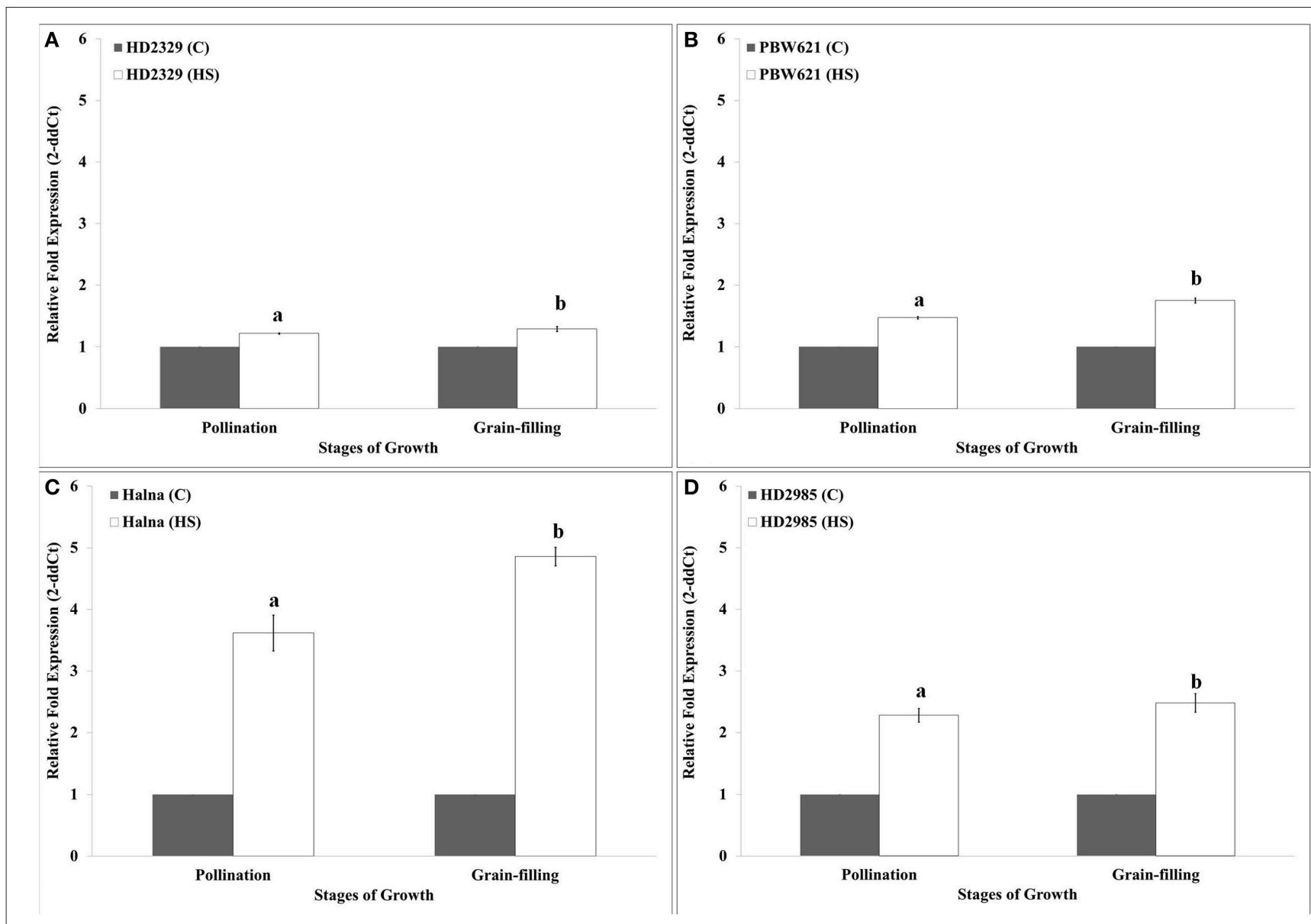

FIGURE 5 | Expression profiling of RuBisCo activase (TaRca1) in wheat during pollination and grain-filling stages under control (C) and heat stress (HS) conditions. (A) HD2329 (C and HS), (B) PBW621(C and HS), (C) Halna (C and HS), (D) HD2985 (C and HS); C -22 $\pm 3^{\circ}$, heat stress -42 ${ }^{\circ} \mathrm{C}$ for 2 h; $\beta$-actin gene (accession no. AF282624) was used as endogenous control for normalizing the $C_{t}$ value; Relative expression was calculated by Pfaffl method (Pfaffl et al., 2002); vertical bars indicate SE $(n=3)$.

stems, and spikes (sink); however, carbon partitioning and stemreserve mobilization varies with the environmental temperature. HD2329 showed maximum accumulation of reducing sugar in stem during mealy-ripe stage (18 mg/g fresh weight) under control condition. HS causes drastic reduction in the accumulation of reducing sugar in stem of HD2329 during mealy-ripe stage (Figure 9). Similar pattern of reducing sugar accumulation was observed in stems of other cultivars (HD2985, PBW621, and Halna) in response to control and HS-treated conditions (Figure 9). Halna showed maximum accumulation of reducing sugar $(21.5 \mathrm{mg} / \mathrm{g}$ fresh weight) in stem during mealyripe stage, as compared to other cvs. under control condition. Similarly, under HS, stem of HD2329 showed maximum accumulation of reducing sugar $(10 \mathrm{mg} / \mathrm{g} \mathrm{FW})$ compared to other cultivars.

Reducing sugar estimation in leaves of wheat $c v$. HD2329 showed maximum accumulation during mealy-ripe stage under control (4.4 mg/g FW) and HS-treated (2.1 mg/g FW) conditions. Similar pattern of accumulation of reducing sugar was observed in other wheat $c v s$. at different sub-stages of grain-filing under control and HS-treated conditions. Leaves of HD2985 showed maximum accumulation of reducing sugar during mealy-ripe stage under control and HS-treated conditions, as compared to other cultivars (Figure 9).

HD2329 showed maximum accumulation of non-reducing sugar in stem during mealy-ripe under control $(27 \mathrm{mg} / \mathrm{g} \mathrm{FW})$ condition, which drastically decrease under HS (10 mg/g FW) (Figure 10). Similar pattern of non-reducing sugar accumulation was observed in stem of PBW621 under control and HStreated conditions. Halna showed maximum accumulation of non-reducing sugar in stem during milky-ripe stage (11.5 $\mathrm{mg} / \mathrm{g} \mathrm{FW}$ ) under control condition (Figure 10). We observed significant decrease in the non-reducing sugar accumulation in stem of PBW621 under HS at different sub-stages of grain-filling. Non-reducing sugar accumulation was observed minimum in stem of HD2985 compared to other cvs., both at milky- and mealy-ripe stages under control and HS-treated conditions. Non-reducing sugar content in leaves of HD2329 showed maximum accumulation during mealy-ripe stage under control and HS-treated conditions. Non-significant variations 


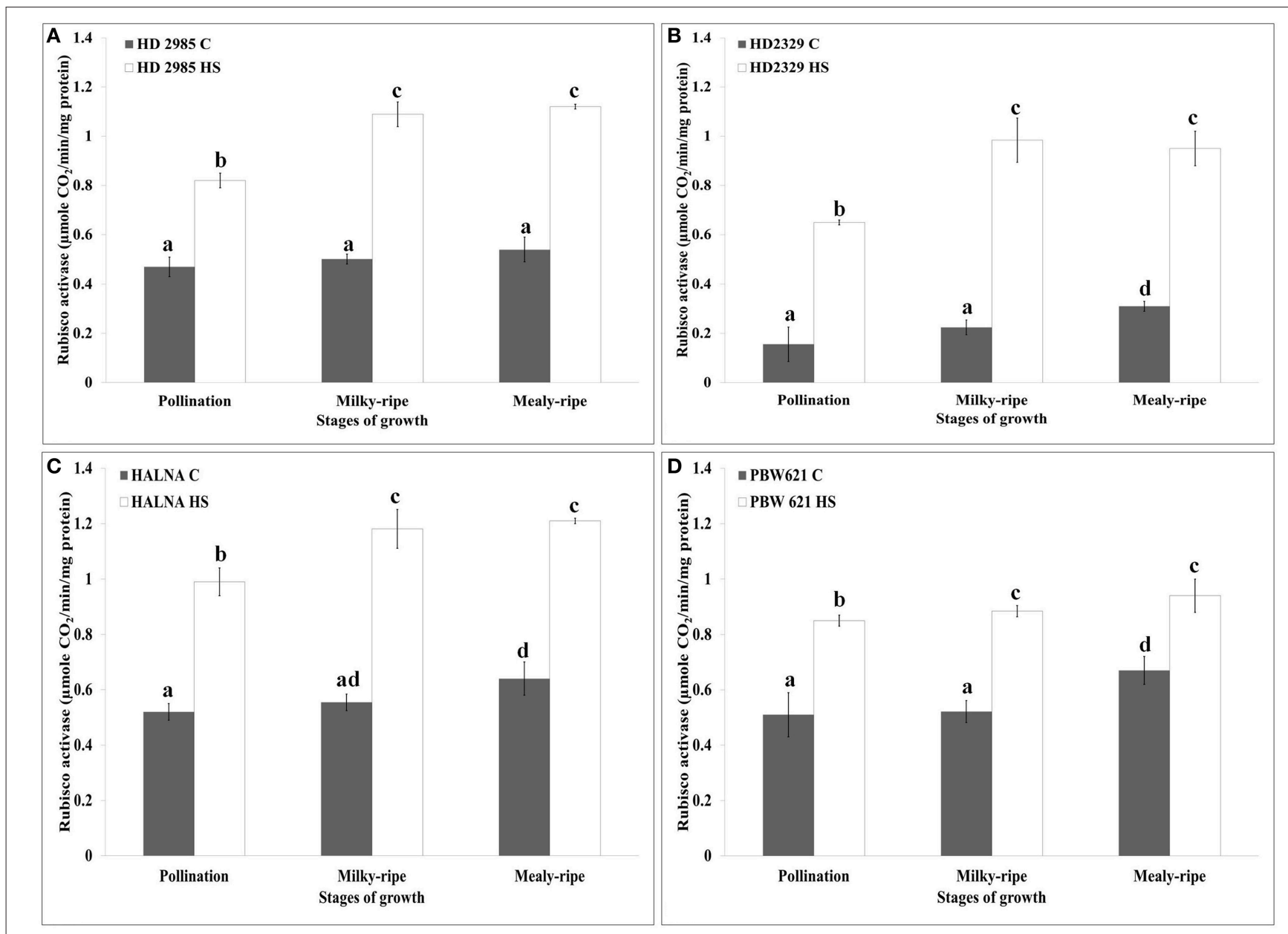

FIGURE 6 | RuBisCo activase (Rca) activity assay in contrasting wheat cultivars at different stages of growth and development under control (C) and heat stress (HS) conditions. (A) HD2985 (C and HS), (B) HD2329 (C and HS), (C) Halna (C and HS), (D) PBW621 (C and HS); samples collected from pollination, milky-ripe and mealy-ripe stages were used for the activity assay; $\mathrm{C}-22 \pm 3^{\circ}$, heat stress $-42^{\circ} \mathrm{C}$ for $2 \mathrm{~h}$; $\mathrm{NaH}^{14} \mathrm{CO}_{3}\left(20 \mathrm{mM}, \mathrm{specific}\right.$ activity $50 \mathrm{mCi} \mathrm{mmol}{ }^{-1}$, BARC, Mumbai) was used for the labeling; different letters above each bar indicate a significant difference $(p<0.05)$ between the treatments (one-way ANOVA); vertical bars indicate SE $(n=3)$.

in the non-reducing sugar accumulation were observed in PBW621 under control and HS-treated conditions. Halna showed maximum accumulation of non-reducing sugar in leaves during milky-ripe, both under control and HS-treated conditions, which reduces subsequently during mealy-ripe stage. Similar pattern of non-reducing sugar accumulation in leaves of HD2985 was observed under control and HS-treated conditions (Figure 10). Non-reducing sugar in leaves of HD2985 decreased significantly under the control and HS-treated conditions during the grain-filling; decrease was more during the milky-ripe stage.

\section{Variation in the Total Antioxidant Capacity (TAC) under HS}

TAC is a measure of the antioxidant potential of the tissues, and is one of the important biochemical parameters used for assessing the thermotolerance of crops. We observed significant decrease in the TAC in HD2985 during mealy-ripe, as compared to pollination and milky-ripe stages (Figure 11). An increase in the TAC was observed in response to HS at different stages of development. Similar pattern of TAC was observed in HD2329 (thermosensitive $c v$.) under the control and HS-treated conditions, but TAC was significantly lower than those in HD2985 at all the stages and under different conditions. Significant increase in the TAC, both under control and HS-treated conditions, at different stages of growth were observed in Halna; highest, being during mealy-ripe. We observed significant increase in the TAC in response to HS during pollination, milky-ripe, and mealy-ripe stages of Halna; highest at the mealy-ripe sub-stage. Similar pattern was observed in PBW621; increase in TAC due to HS was quite significant. During the pre-anthesis and milkyripe stages, highest TAC were observed in HS-treated HD2985 (26.7 and $23 \mathrm{mM} / \mathrm{g} \mathrm{FW}$ ), whereas HS-treated Halna showed highest TAC $(27.8 \mathrm{mM} / \mathrm{g} \mathrm{FW})$ during the mealy-ripe stage. Maximum increase in the TAC in response to HS was observed 


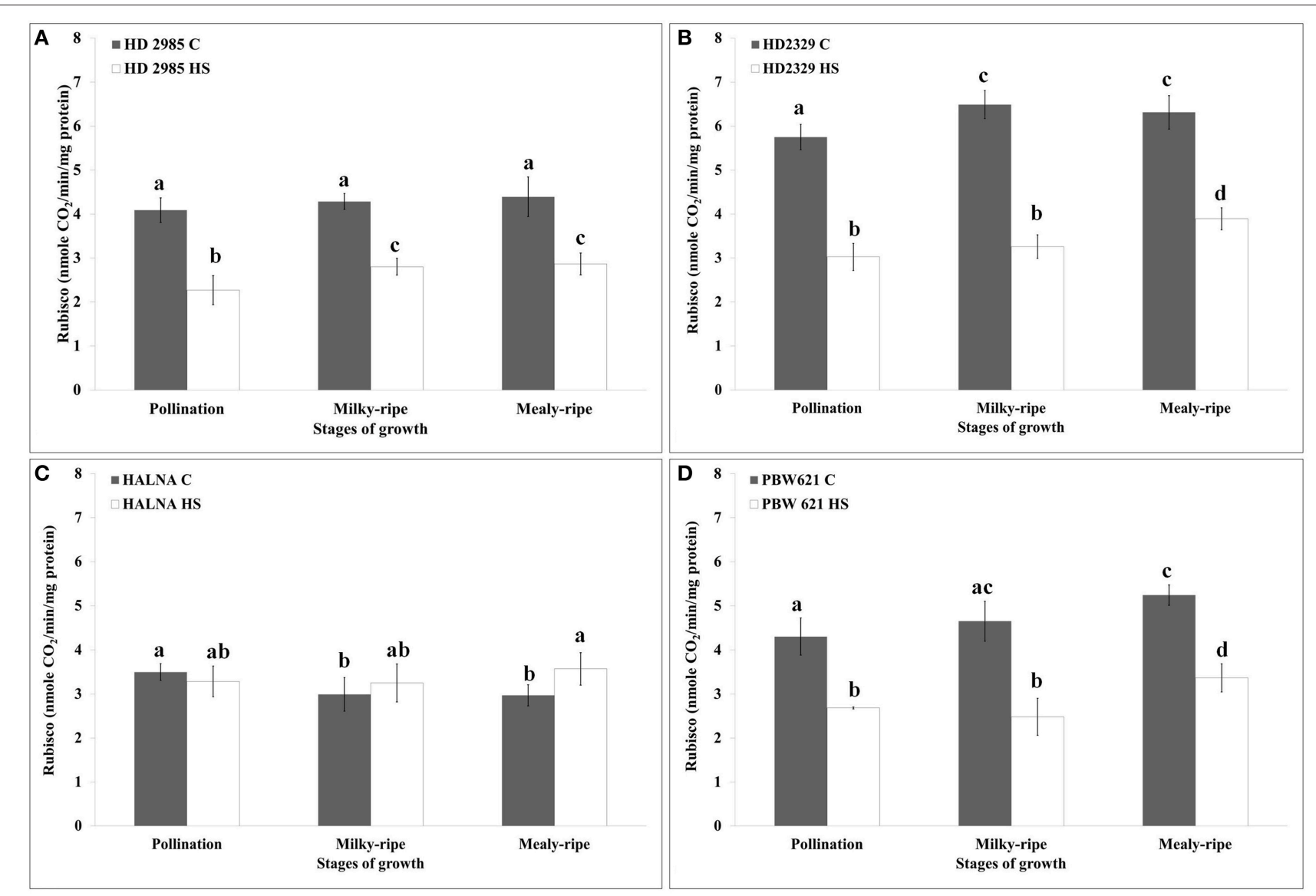

FIGURE 7 | Variations in the RuBisCo activity in contrasting wheat cultivars under control (C) and heat stress (HS) conditions at different stages of growth. (A) HD2985 (C and HS), (B) HD2329 (C and HS), (C) Halna (C and HS), (D) PBW621 (C and HS); samples collected from pollination, milky-ripe and mealy-ripe stages were used for the activity assay; $\mathrm{C}-22 \pm 3^{\circ}$, heat stress $-42^{\circ} \mathrm{C}$ for $2 \mathrm{~h}$; $\mathrm{NaH}^{14} \mathrm{CO}_{3}\left(20 \mathrm{mM}, \mathrm{specific}\right.$ activity $50 \mathrm{mCi} \mathrm{mmol}{ }^{-1}$, BARC, Mumbai) was used for the labeling; different letters above each bar indicate a significant difference $(p<0.05)$ between the treatments (one-way ANOVA); vertical bars indicate $\mathrm{SE}(n=3)$.

in HD2985 during the pollination (25.8\%) and milky-ripe $(22.3 \%)$ and in Halna $(27.2 \%)$ during the mealy-ripe stage (Figure 11).

\section{Correlation between the Expression and Activities of Rca and RuBisCo under HS}

To correlate the transcript level and protein activity of TaRcal in Halna, PBW621, HD2985, and HD2329, cluster map analysis was carried out under HS-treated condition. A positive correlation was observed between the relative expression of TaRcal and its activity in HS-treated Halna $\left(R^{2}=0.97\right)$ and PBW621 $\left(R^{2}=\right.$ 0.98); HS-treated HD2985 and HD2329 showed correlation coefficients of 0.93 and 0.94 , respectively (Figures 12A,B).

The Rca activity was also found correlated with the RuBisCo activity in wheat under HS; positive correlation was established in Halna (HS-treated) with $R^{2}=0.85$ and negative correlation was observed in Halna (control) with $R^{2}=-0.86$. The correlation was further analyzed and confirmed in the thermotolerant wheat cv. PBW621-positive correlation in control (0.98) and HStreated (0.97) was observed (Figures 12C,D).

\section{Correlation between Rca/RuBisCo Activities and Photosynthetic Rate under HS}

To establish the relationship of Rca and RuBisCo activities with overall photosynthetic rate of wheat under HS, scatter-plot analysis was carried out and we observed positive correlation between the RuBisCo activity and photosynthetic rate in wheat cvs. HD2985 (0.98) and HD2329 (0.92); however Rca showed negative correlation with the photosynthetic rate in both the cultivars with $R^{2}$-values of -0.97 and -0.95 , respectively (Figures 13A,B).

\section{DISCUSSION}

Wheat is highly-sensitive to HS which results in drastic reduction in photosynthetic rate and translocation of photosynthates from leaves (source) to the endospermic tissues (sink), culminating into significant reduction in the yield. Even slight fluctuation in the temperature during the critical stages such as pollination and 

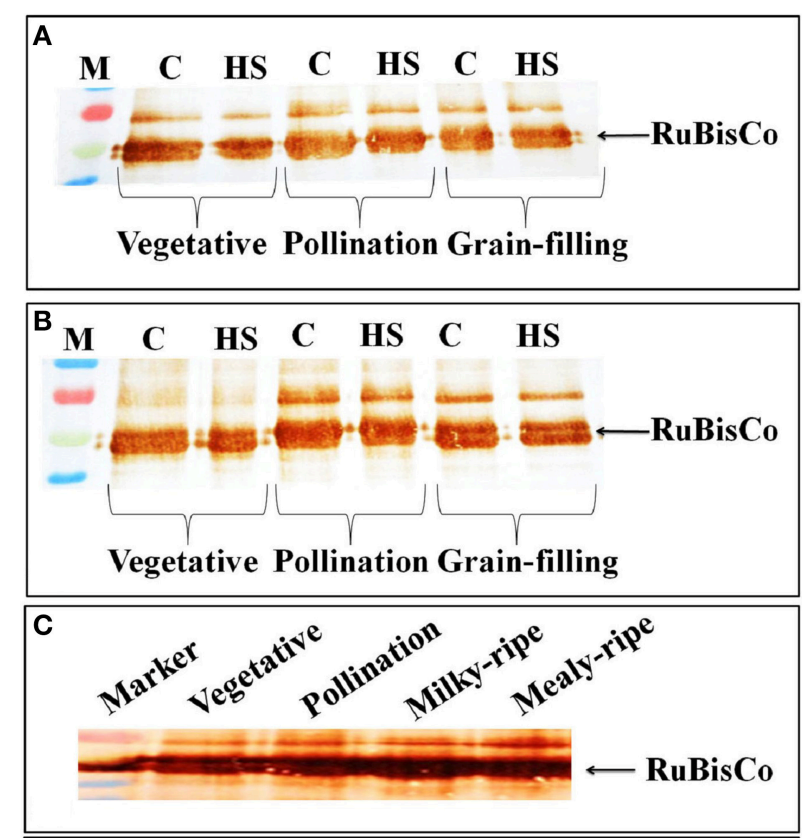

D

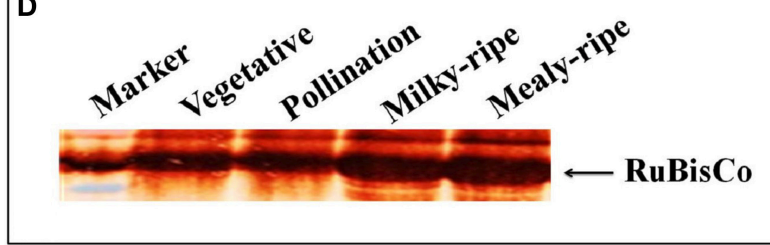

FIGURE 8 | Accumulation pattern of RuBisCo in wheat at different stages of growth and under heat stress. (A) RuBisCo accumulation in HD2329 under control and HS, (B) RuBisCo accumulation in HD2985 under control and HS, (C) RuBisCo accumulation in HD2985 at different stages of growth, (D) RuBisCo accumulation in HD2329 at different stages of growth; C $-22 \pm 3^{\circ}$, heat stress $-42^{\circ} \mathrm{C}$ for $2 \mathrm{~h}$; Polyclonal antibody (anti-RuBisCo) was used along with HRP-conjugated secondary antibody; different letters above each bar indicate a significant difference $(p<0.05)$ between the treatments (one-way ANOVA); vertical bars indicate SE $(n=3)$.

grain-filling has been reported to significantly reduce the yield of wheat.

We identified eight transcripts of Rca by mining the RNA-seq data and cloned a full-length putative Rca transcript of $1402 \mathrm{nt}$ with an open reading frame of 332 aa. Law and Crafts-Brandner (1999) have reported two isoforms of $R c a-\alpha$-isoform $(46 \mathrm{kDa})$ and $\beta$-isoform ( $42 \mathrm{kDa}$ ) - in leaves of wheat. Using the genome database for the Chinese spring wheat (IWGSC, 2014), two Rca sequences were identified in wheat with different isoformsTaRca-1 and TaRca2; the genes were cloned and submitted to EMBL (http://www.ebi.ac.uk/ena/) under the accession numbers LM992844 (TaRca1- $\beta$ ), LM992845 (TaRca2- $\beta$ ), and LM992846 (TaRca2- $\alpha$ ). Genome-wide survey revealed the presence of $\alpha$ and $\beta$-form $R c a$ in the maize genome ( $Z m R C A \alpha$ and $Z m R C A \beta$; Yin et al., 2014). Southern blot analysis showed the presence of single copy of the cloned TaRcal gene in wheat which is in conformity with the observation of Law and Crafts-Brandner (1999), who reported the presence of single copy number of Rca gene in wheat; similar findings were reported by To et al. (1999) in Oryza sativa.

We observed significant increase in the expression of Rca in different wheat $c v s$. under HS. Transcriptional analyses showed specific diurnal pattern of expression of $Z m R C A \alpha$ and $Z m R C A \beta$; abundance was observed higher in leaves and grains (Yin et al., 2014). Feng et al. (2007) observed increase in the accumulation of $\mathrm{Rca}$ in the transgenic rice in response to HS, as compared to the wild plants. Diurnal changes in the expression of three isoforms of $R c a$ were observed in cotton under HS (DeRidder and Salvucci, 2007). Very high accumulation of RcaL isoform, as compared with that of RcaS, was observed in the leaves and green stems of Brachypodium distachyon, under the salt and drought stress, respectively (Bayramov and Guliyev, 2014). Alternative splicing has been reported to play a role in the post-transcriptional regulation of $R c a$, in response to different growth and stress conditions (DeRidder et al., 2012). A significant, positive, and linear correlation has been reported between the expression of wheat $45-46 \mathrm{kDa} \mathrm{Rca}$ and plant productivity, under the heatstress condition in wheat (Ristic et al., 2009). Here, we observed that heat stress significantly induces the expression and activity of Rca, which is in conformity with the report of Wang D. et al. (2010) in rice.

We observed increase in the activity of Rca in response to HS in the contrasting wheat cvs.; highest activity was observed in the thermotolerant cultivars (Halna and HD2985) during the mealy-ripe stage. Rokka et al. (2001) have reported temperature-dependent dual role of Rca-removing inhibitory sugar phosphates under the normal ambient temperatures, and acting as chaperone along with thylakoid-bound ribosomes, under the sudden outburst of temperature (HS). Salvucci et al. (2001) studied thermal stability of Rca in vivo and in vitro, and reported that the activase exhibits a temperature optimum of $44^{\circ} \mathrm{C}$ for ATP hydrolysis as compared to $\geq 60^{\circ} \mathrm{C}$ for carboxylation by RuBisCo. Salvucci and Crafts-Brandner (2004a) reported decreased ability of Rca to activate RuBisCo in vitro under HS. The transcript abundance and protein expression levels of Rca genes were found to be positively correlated with grain yield in 128 maize inbred lines (Yin et al., 2014). We observed increase in the $\mathrm{RuBisCo}$ proteins in response to HS in all the $c v s$. The finding is in conformity with the observation of Demirevska-Kepova et al. (2005) in wheat under differential HS.

We observed decrease in the activity of RuBisCo under HS; the decrease may be due to less availability of the activated enzyme under HS (Galmes et al., 2013). The rate of deactivation of RuBisCo was observed to increase with increase in the temperature (Salvucci and Crafts-Brandner, 2004c). The activation state of RuBisCo was reported to decrease, along with the inhibition of Rca, in HS-treated cotton and extent of RuBisCo deactivation was correlated with the metabolic limitation to photosynthesis (Carmo-Silva et al., 2012). Salvucci and CraftsBrandner (2004c) showed that RuBisCo was inactivated within $7 \mathrm{~s}$ of imposing a heat stress in cotton and tobacco due to decrease in the activase activity.

Under the present investigation, we observed increase in the accumulation of RuBisCo protein at different stages of growth under the control; however, decrease in RuBisCo accumulation 


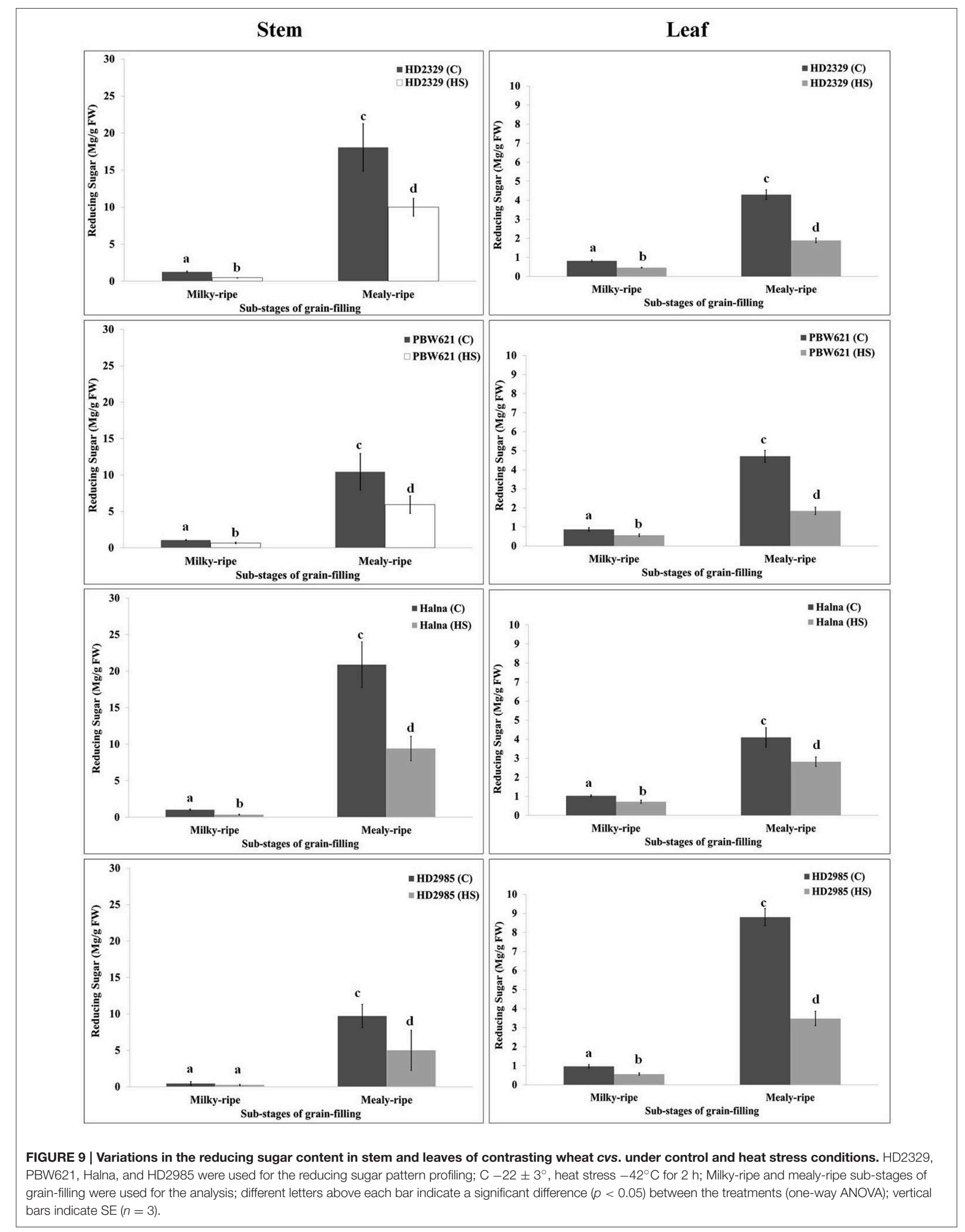




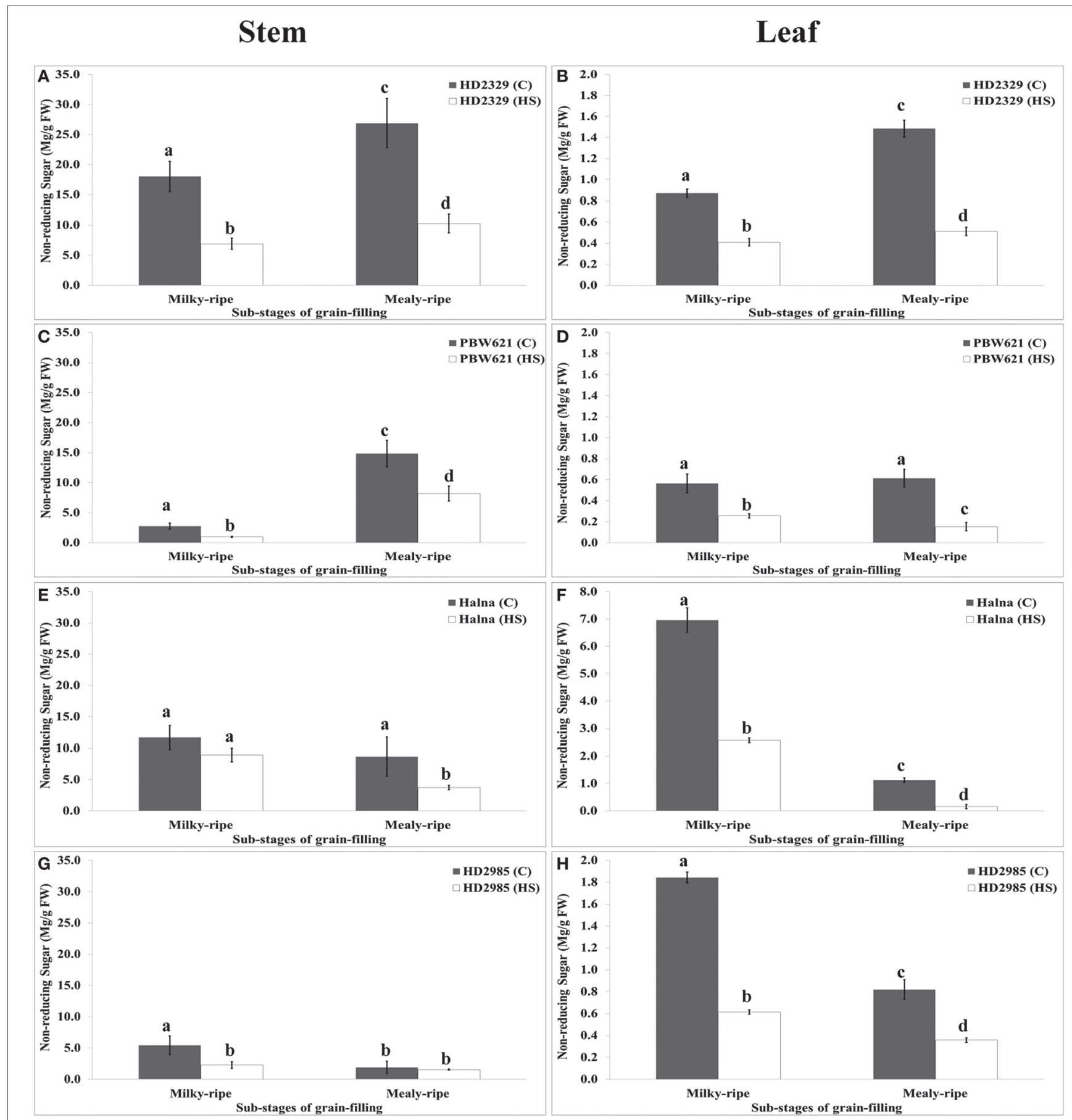

FIGURE 10 | Changes in the non-reducing sugar accumulation in stem and leaves of wheat cvs. under control and heat stress conditions. (A,B) Non-reducing sugar content in stem and leaf of HD2329, (C,D) Non-reducing sugar accumulation in stem and leaf of PBW621, (E,F) Non-reducing sugar content in stem and leaf of Halna, (G,H) Non-reducing sugar accumulation in stem and leaf of HD2985. Thermosusceptible (HD2329 and PBW621) and thermotolerant (Halna and HD2985) were used for the non-reducing sugar accumulation pattern analysis; $\mathrm{C}-22 \pm 3^{\circ}$, heat stress $-42^{\circ} \mathrm{C}$ for $2 \mathrm{~h}$; Milky-ripe and mealy-ripe sub-stages of grain-filling were used for the analysis; different letters above each bar indicate a significant difference $(p<0.05)$ between the treatments (one-way ANOVA); vertical bars indicate SE $(n=3)$

was observed in response to $\mathrm{HS}\left(38^{\circ} \mathrm{C}, 2 \mathrm{~h}\right)$. The finding is in conformity with the observation of Demirevska-Kepova et al. (2005) who reported decrease in the RuBisCo protein under HS in wheat. Similar observations have been reported in response to different stresses in plants (Wang D. et al., 2010; Galmes et al., 2013) observed through immunoblot analysis that the ratio of $\mathrm{RCA}_{\mathrm{L}}$ to RuBisCo increased significantly in heat-acclimated rice leaves. 


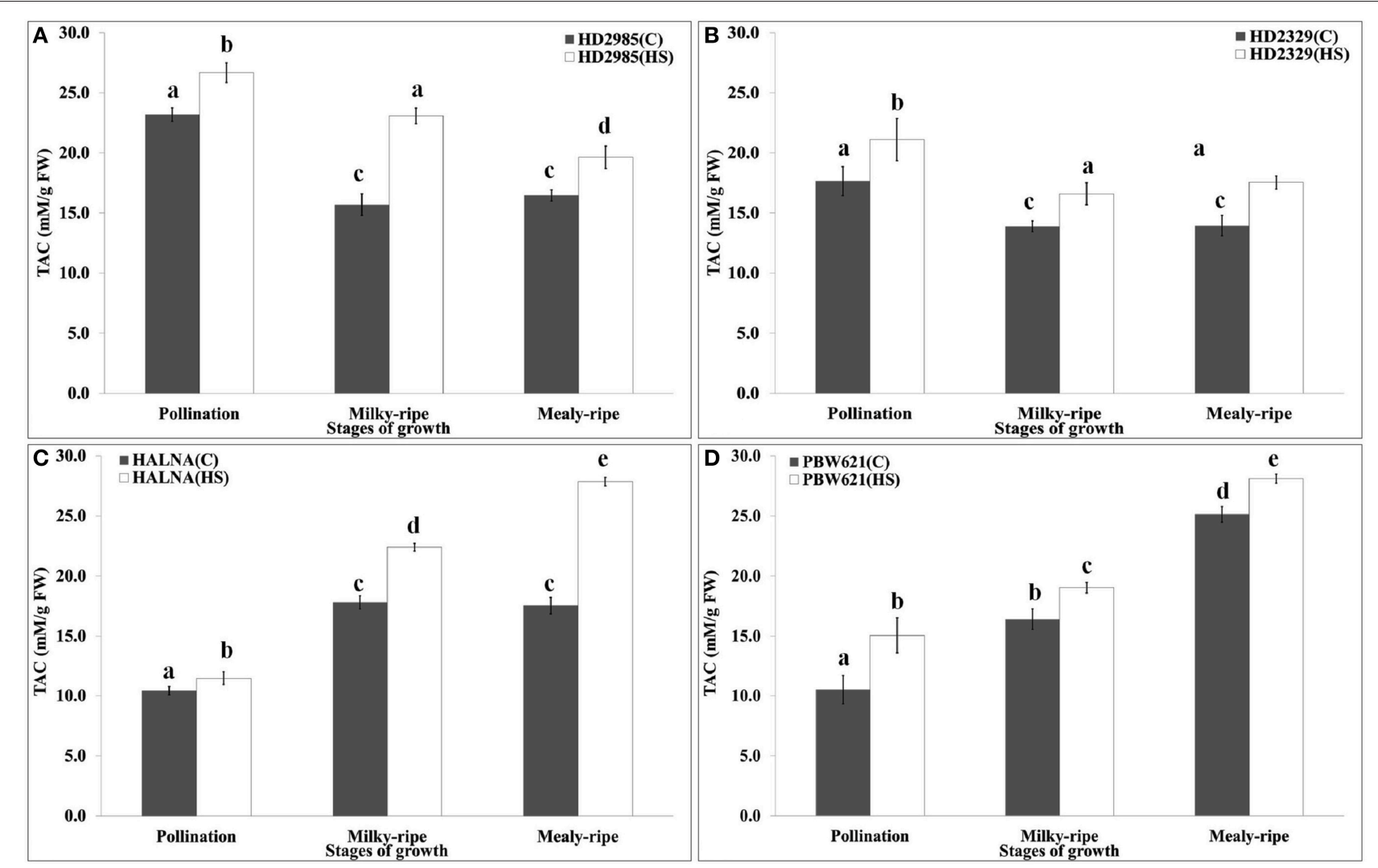

FIGURE 11 | Total Antioxidant Capacity (TAC) profiling of contrasting wheat cultivars at different stages of development and under the heat stress. (A) TAC in HD2985, (B) TAC in HD2329, (C) TAC in Halna, (D) TAC in PBW621; Samples collected from the pollination, milky-ripe and mealy-ripe stages were used for the TAC estimation; $\mathrm{C}-22 \pm 3^{\circ}$, heat stress $-42^{\circ} \mathrm{C}$ for $2 \mathrm{~h}$; vertical bars indicate $\mathrm{SE}(n=3)$.

An alteration in RuBisCo and Rca activities under HS causes change in the carbon assimilatory processes, which is evident from the increased level of non-reducing sugar in the leaves and stem. Stem-reserves have been recognized as an important source of carbon for grain-filling, when photosynthesis is inhibited by the abiotic stresses such as heat and drought (Blum, 1998). Accumulation of sugars in stem has been predicted to be an adaptive strategy against different stresses, as found in different genotypes of sorghum under the drought stress (Quazi et al., 2014). Asthir and Bhatia (2014) have reported that HS causes built-up of total free sugars and decreases the starch content of grains in wheat. Similar finding were reported by Kumar and Rai (2014). Liu and Huang (2000) have also observed decrease in the total non-structural carbohydrates (TNC), fructans, starch, glucose, and sucrose in shoots (leaves and stems) and roots in response to HS in the bentgrass cultivars. Increase in the TAC under HS with greater increase in thermotolerant is in agreement with the findings of Chakrabortty and Pradhan (2011) that the activities of the antioxidant enzymes involved in thermotolerance goes up under HS; similar observations were reported by us also Kumar et al. (2013) and Kumar and Rai (2014).

Photosynthetic rate decreased under HS in all the cultivars, except in PBW621 where increase in the $\mathrm{P}_{\mathrm{n}}$ was observed. Farooq et al. (2011) reported reduction in the photosynthetic capacity of the plant under HS, mainly due to the oxidative damage to the chloroplasts, causing reductions in the dry matter accumulation and grain yield. Similarly, Wang G.P. et al. (2010) observed increase in the transpiration rate $\left(\mathrm{T}_{\mathrm{r}}\right)$, stomatal conductance $\left(\mathrm{G}_{\mathrm{s}}\right)$, and intercellular $\mathrm{CO}_{2}$ concentration $\left(\mathrm{C}_{\mathrm{i}}\right)$, and decrease in the photosynthetic rate in wheat under heat stress.

Yamori et al. (2012) reported that $\mathrm{HS}$ of $40^{\circ} \mathrm{C}$ caused decrease in the accumulation of Rca, which in turn reduced the RuBisCo activation state and steady-state photosynthesis, is concordant with the findings of this study. Higher RuBisCo activation and $\mathrm{CO}_{2}$ assimilation were observed in rice, with over-expressed Rca (Fukayama et al., 2012). Here, we observed negative correlation between the Rca and photosynthetic rate of wheat under HS. Sage et al. (2008) reported that Rca, being highly heat-labile, shown to limit the photosynthesis under the slightest fluctuation in temperature. Similar finding was reported by Salvucci and Crafts-Brandner (2004b) in wheat under HS. Similarly, positive correlation of $\mathrm{P}_{\mathrm{n}}$ with the RuBisCo activity and negative with Rca activity under the HS, as observed in present investigation is contrary to the findings of Wang G. P. et al. (2010) who reported positive correlation between the Rca protein content, RuBisCo initial activity and net photosynthetic rate (Pn) under normal 


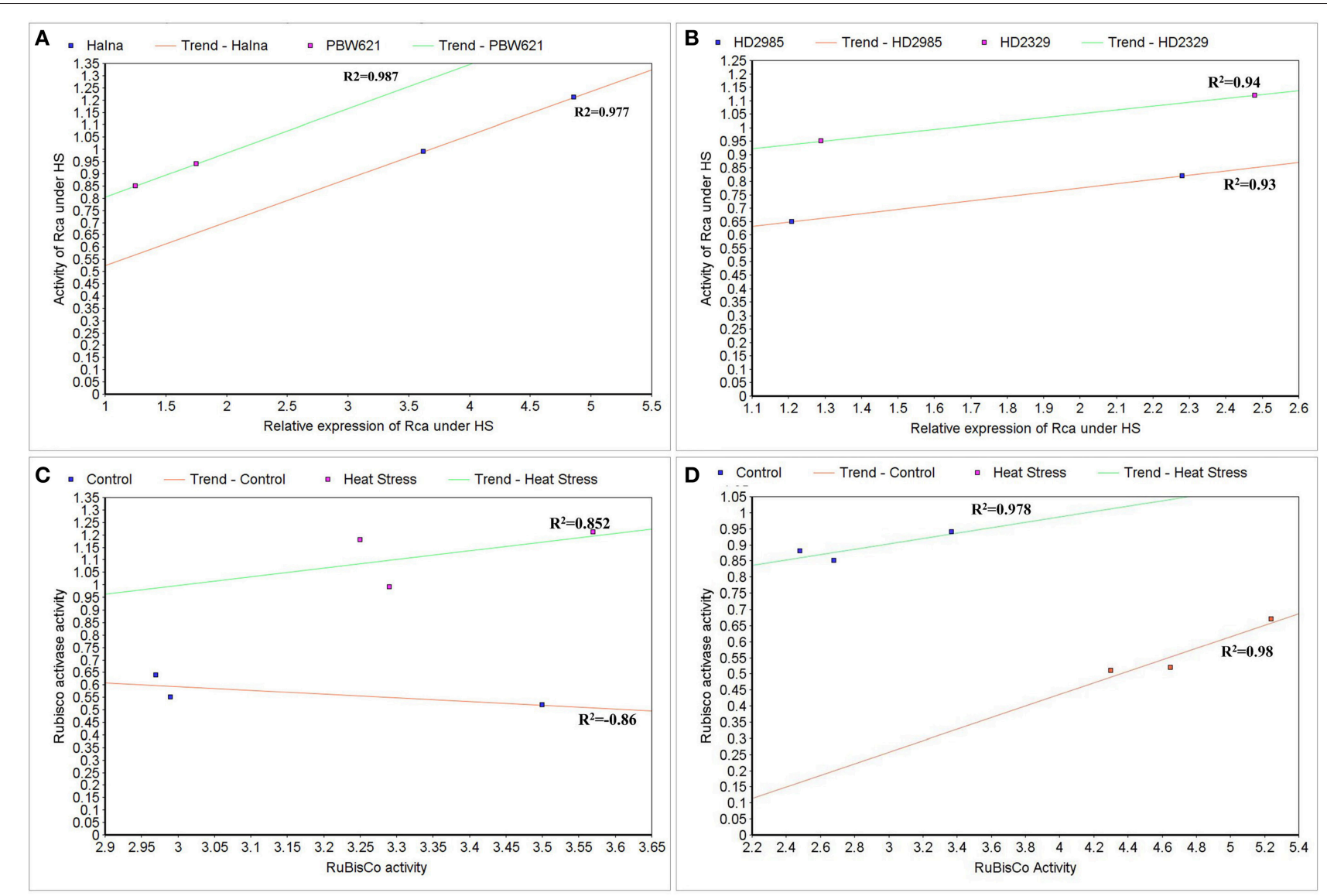

FIGURE 12 | Cluster-map for analyzing the correlation between expression and activity of RuBisCo activase (Rca) and RuBisCo under control and heat stress conditions. (A) Correlation between the expression and activity of Rca in Halna and PBW621 (C and HS), (B) Correlation between the expression and activity of Rca in HD2985 and HD2329 (C and HS), (C) Correlation between the activity of Rca and RuBisCo in Halna (C and HS), (D) Correlation between the expression and activity of Rca and RuBisCo in PBW621 (C and HS); $\mathrm{C}-22 \pm 3^{\circ}$, heat stress $-42^{\circ} \mathrm{C}$ for $2 \mathrm{~h}$.

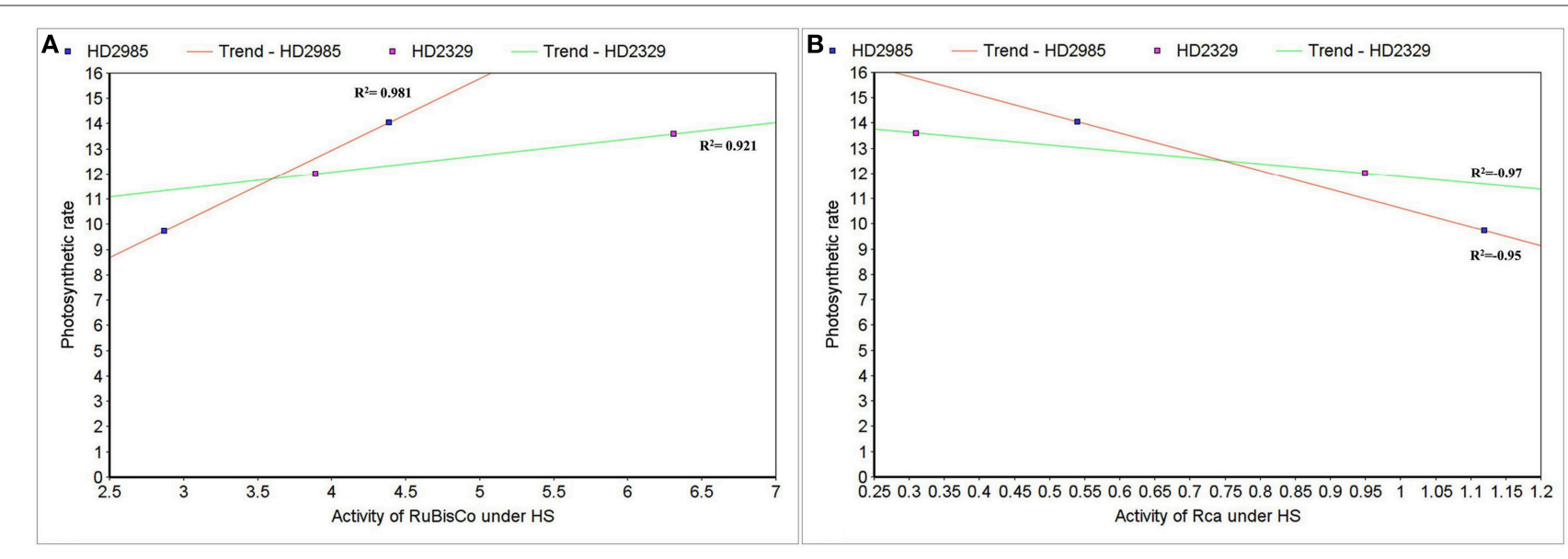

FIGURE 13 | Correlating the activity of RuBisCo activase (Rca) and RuBisCo with photosynthetic rate in wheat under the heat stress. (A) Cluster-map analysis of RuBisCo activity with photosynthetic rate in HD2985 and HD2329 under HS, (B) Cluster-map analysis of Rca activity with photosynthetic rate in HD2985 and HD2329 under HS. 
and HS conditions; dual role of Rca under the ambient and HS conditions may be one of the reason (Rokka et al., 2001). Negative correlation between RuBisCo and Rca observed in Halna could not be explained.

\section{CONCLUSION}

We identified eight putative transcripts of $R c a$ by mining NGS data and cloned a novel TaRcal gene of 1402 bp from wheat $c v$. HD2985. Single copy of the cloned TaRcal was observed in wheat genome. Expression and activity of TaRCal was observed maximum in Halna during pollination and grain-filling under control and HS, as compared to HD2985, HD2329, and PBW621. An increase in the RuBisCo activity was observed in Halna during grain-filling under HS. We observed negative correlation between the RuBisCo activity and protein accumulation, as validated through Immunoblot analysis under control and HS conditions. A positive correlation was established between the expression and activity of RuBisCo and TaRcal under HS; proper distributions of reducing and non-reducing sugars were observed in cultivars having high activity of RuBisCo and Rca. TAC was observed higher in $c v$. with maximum RuBisCo and Rca activities. TaRcal has the potential to modulate the activity of RuBisCo under HS and provides the most probable solution for mitigating the HS problem in wheat.

\section{AUTHOR CONTRIBUTIONS}

RK and SG conceived and designed the experiment; KS, KD, RS, and YK performed the heat stress treatment, sample collection, activity assay, and Real-Time PCR; NV, SS, DM, MG, and AR

\section{REFERENCES}

Andersson, I., and Backlund, A. (2008). Structure and function of RuBisCo. Plant Physiol. Biochem. 46, 275-291. doi: 10.1016/j.plaphy.2008.01.001

Asthir, B., and Bhatia, S. (2014). In vivo studies on artificial induction of thermotolerance to detached panicles of wheat (Triticum aestivum $\mathrm{L}$ ) cultivars under heat stress. J. Food Sci. Technol. 51, 118-123. doi: 10.1007/s13197-0110458-1

Bayramov, S., and Guliyev, N. (2014). Changes in RuBisCo activase gene expression and polypeptide content in Brachypodium distachyon. Plant Physiol. Biochem. 81, 61-66. doi: 10.1016/j.plaphy.2014.01.013

Benzie, I. F., and Strain, J. J. (1999). Ferric reducing/antioxidant power assay: direct measure of total antioxidant activity of biological fluids and modified version for simultaneous measurement of total antioxidant power and ascorbic acid concentration. Meth. Enzymol. 1, 15-27. doi: 10.1016/S0076-6879(99)99005-5

Bita, C. E., and Gerats, T. (2013). Plant tolerance to high temperature in a changing environment: scientific fundamentals and production of heat stress-tolerant crops. Front. Plant Sci. 4:273. doi: 10.3389/fpls.2013.00273

Blum, A. (1998). Improving wheat grain filling under stress by stem reserve mobilisation. Euphytica 100, 77-83. doi: 10.1023/A:1018303922482

Bradford, M. M. (1976). Rapid and sensitive method for the quantitation of microgram quantities of protein utilizing the principle of protein-dye binding. Anal. Biochem. 72, 248-254. doi: 10.1016/0003-2697(76)90527-3

Carmo-Silva, A. E., Gore, M. A., Andrade-Sanchez, P., French, A. N., Hunsaker, D. J., and Salvucci, M. E. (2012). Decreased $\mathrm{CO}_{2}$ availability and inactivation of RuBisCo limit photosynthesis in cotton plants under heat and drought stress in the field. Env. Exp. Bot. 83, 1-11. doi: 10.1016/j.envexpbot.2012.04.001

Chakrabortty, U., and Pradhan, D. (2011). High temperature-induced oxidative stress in Lens culinaris, role of antioxidants and amelioration performed the data analysis; BS and GR, performed the RuBisCo and Rca activity assay; HP and VC executed the IRGA experiment and correlated the derived results; RR, SG, SP, and VC wrote the manuscript; all authors contributed to the discussion and approved the final manuscript.

\section{ACKNOWLEDGMENTS}

We acknowledge the grant received from Science and Engineering Research Board (SERB), Department of Science and Technology (DST), Government of India (GOI; sanction no $\mathrm{SERB} / \mathrm{SB} / \mathrm{SO} / \mathrm{PS} / 07 / 2014)$. Bioinformatics support given by the scientists of ICAR-IASRI is highly acknowledged. We are also thankful to ICAR, GOI for providing the fund under the CABin project (sanction no 21-56; TG3064).

\section{SUPPLEMENTARY MATERIAL}

The Supplementary Material for this article can be found online at: http://journal.frontiersin.org/article/10.3389/fpls.2016. 00986

Figure S1 | Work-plan depicting the layout for the sowing, heat shock treatment and samples collection at different stages of growth and development for downstream analysis.

Table S1 | List of putative RuBisCo activase genes identified by mining of de novo transcriptome data generated from control and heat shock-treated wheat cv. HD2985 using next-generation sequencing (NGS) platform.

Table S2 | Identification of putative RuBisCo activase (Rca) transcript sequences from control and HS-treated wheat cv. HD2985 using RNA-seq.

Table S3 | List of primers used for the cloning and expression study of RuBisCo activase (TaRca1) by quantitative real-time PCR (qRT-PCR).

of stress by chemical pre-treatments. J. Plant Interact. 6, 43-52. doi: 10.1080/17429145.2010.513484

Cleland, W. W., Andrews, T. J., Gutteridge, S., Hartman, F. C., and Lorimer, G. H. (1998). Mechanism of RuBisCo: the carbamate as general base. Chem. Rev. 98, 549-561. doi: 10.1021/cr970010r

Demirevska-Kepova, K., Holzer, R., Simova-Stoilova, L., and Feller, U. (2005). Heat stress effects on ribulose-1, 5-bisphosphate carboxylase/oxygenase, RuBisCo binding protein and RuBisCo activase in wheat leaves. Biol Plant. 49, 521-525. doi: 10.1007/s10535-005-0045-2

DeRidder, B. P., and Salvucci, M. E. (2007). Modulation of RuBisCo activase gene expression during heat stress in cotton (Gossypium hirsutum L.) involves post-transcriptional mechanisms. Plant Sci. 172, 246-254. doi: 10.1016/j.plantsci.2006.08.014

DeRidder, B., Shybut, M., Dyle, M., Kremling, K. G., and Shapiro, M. (2012). Changes at the $3^{\prime}$-untranslated region stabilize RuBisCo activase transcript levels during heat stress in Arabidopsis. Planta 236, 463-476. doi: 10.1007/s00425-012-1623-0

Dubois, M., Gilles, K. A., Hamilton, J. K., Rebers, P., and Smith, F. (1956). Colorimetric method for determination of sugars and related substances. Anal. Chem. 28, 350-356. doi: 10.1021/ac60111a017

Farooq, M., Bramley, H., Palta, J. A., and Siddique, K. H. M. (2011). Heat stress in wheat during reproductive and grain-filling phases. Crit Rev Plant Sci. 30, 491-507. doi: 10.1080/07352689.2011.615687

Feng, L., Wang, K., Li, Y., Tan, Y., Kong, J., Li, H., et al. (2007). Overexpression of SBPase enhances photosynthesis against high temperature stress in transgenic rice plants. Plant Cell Rep. 26, 1635-1646. doi: 10.1007/s00299-0060299-y

Fukayama, H., Ueguchi, C., Nishikawa, K., Katoh, N., Ishikawa, C., Masumoto, C., et al. (2012). Overexpression of RuBisCo activase decreases the photosynthetic 
$\mathrm{CO}_{2}$ assimilation rate by reducing RuBisCo content in rice leaves. Plant Cell Physiol. 53, 976-986. doi: 10.1093/pcp/pcs042

Galmes, J., Aranjuelo, I., Medrano, H., and Flexas, J. (2013). Variation in RuBisCo content and activity under variable climatic factors. Photosyn Res. 117, 73-90. doi: 10.1007/s11120-013-9861-y

He, Z. L., von Caemmerer, S., Hudson, G. S., Price, G. D., Badger, M. R., and Andrews, T. J. (1997). Ribulose-1,5-bisphosphate carboxylase/ oxygenase activase deficiency delays senescence of ribulose-1, 5-bisphosphate carboxylase/oxygenase but progressively impairs its catalysis during tobacco leaf development. Plant Physiol. 115, 1569-1580. doi: 10.1104/pp.115.4.1569

International Wheat Genome Sequencing Consortium (IWGSC) (2014). A chromosome-based draft sequence of the hexaploid bread wheat (Triticum aestivum) genome. Science 345:1251788. doi: 10.1126/science.1251788

Jordan, D. B., and Ogren, W. L. (1981). Species variation in the specificity of ribulose bisphosphate carboxylase/oxygenase. Nature 291, 513-515. doi: $10.1038 / 291513 \mathrm{a} 0$

Kim, K., and Portis, J. (2004). Oxygen-dependent $\mathrm{H}_{2} \mathrm{O}_{2}$ production by RuBisCo. FEBS Lett. 571, 124-128. doi: 10.1016/j.febslet.2004.06.064

Kotak, S., Larkindale, J., Lee, U., von Koskull-Doring, P., Vierling, E., and Scharf, K. D. (2007). Complexity of the heat stress response in plants. Curr. Opin. Plant Biol. 10, 310-316. doi: 10.1016/j.pbi.2007.04.011

Kumar, R. R., Goswami, S., Sharma, S. K., Kala, Y. K., Rai, G. K., Mishra, D. C., et al. (2015). Harnessing next-generation sequencing in climate change: RNASeq analysis of heat stress-responsive genes in wheat (Triticum aestivum L.). OMICS 19, 632-647. doi: 10.1089/omi.2015.0097

Kumar, R. R., Goswami, S., Sharma, S. K., Singh, K., Gadpayle, K. A., Kumar, N., et al. (2012). Protection against heat stress in wheat involves change in cell membrane stability, antioxidant enzymes, osmolyte, $\mathrm{H}_{2} \mathrm{O}_{2}$ and transcript of heat shock protein. Int. J. Plant Physiol. Biochem. 4, 83-91. doi: 10.5897/IJPPB12.008

Kumar, R. R., and Rai, R. D. (2014). Can wheat beat the heat: understanding the mechanism of thermotolerance in wheat (Triticum aestivum L.). Cereal Res. Commun. 42, 1-18. doi: 10.1556/CRC.42.2014.1.1

Kumar, R. R., Sharma, S. K., Goswami, S., Singh, G. P., Singh, R., Singh, K., et al. (2013). Characterization of differentially expressed stress-associated proteins in starch granule development under heat stress in wheat (Triticum aestivum L.). Ind. J. Biochem. Biophys. 50, 126-138.

Large, E. C. (1954). Growth stages in cereals illustration of the Feekes scale. Plant Pathol. 3, 128-129. doi: 10.1111/j.1365-3059.1954.tb00716.x

Law, R., and Crafts-Brandner, S. J. (1999). Inhibition and acclimation of photosynthesis to heat stress is closely correlated with activation of ribulose - 1, 5-bisphosphate carboxylase / oxygenase. Plant Physiol. 120, 173-182. doi: 10.1104/pp.120.1.173

Law, D. R., Crafts-Brandner, S. J., and Salvucci, M. E. (2001). Heat stress induces the synthesis of a new form of ribulose-1, 5-bisphosphate carboxylase/oxygenase activase in cotton leaves. Planta 214, 117-125. doi: $10.1007 / \mathrm{s} 004250100592$

Liu, X., and Huang, B. (2000). Heat stress injury in relation to membrane lipid peroxidation in creeping bentgrass. Crop Sci. 40, 503-510. doi: $10.2135 /$ cropsci2000.402503x

Long, S. P., and Bernacchi, C. J. (2003). Gas exchange measurements, what can they tell us about the underlying limitations to photosynthesis? Procedures and sources of error. J. Exp. Bot. 54, 2393-2401. doi: 10.1093/jxb/erg262

Miller, G. L. (1959). Use of dinitrosalicylic acid reagent for determination of reducing sugar. Anal. Chem. 31, 426-428. doi: 10.1021/ac601 $47 \mathrm{a} 030$

Parry, M. A. J., Andralojc, P. J., Mitchell, R. A. C., Madgwick, P. J., and Keys, A. J. (2003). Manipulation of RuBisCo: the amount, activity, function and regulation. J. Exp. Bot. 54, 1321-1333. doi: 10.1093/jxb/erg141

Pfaffl, M. W., Horgan, G. W., and Dempfle, L. (2002). Relative expression software tool (REST@) for group-wise comparison and statistical analysis of relative expression results in real-time PCR. Nucleic Acids Res. 30:e36. doi: 10.1093/nar/30.9.e36

Portis, A. R. (2003). RuBisCo activase-RuBisCo's catalytic chaperone. Photosyn Res. 75, 11-27. doi: 10.1023/A:1022458108678

Procunier, J. D., Xu, J., and Kasha, K. J. (1990). A rapid and reliable DNA extraction method for higher plants. Barley Genet. Newsl. 20, 74-75.

Quazi, H. A., Rao, P. S., Kashikar, A., and Suprasanna, P. (2014). Alterations in stem sugar content and metabolism in sorghum genotypes subjected to drought stress. Funct. Plant Biol. 41, 954-962. doi: 10.1071/ FP13299

Ristic, Z., Momcilovic, I., Bukovnik, U., Prasad, P. V., Fu, J., DeRidder, B. P., et al. (2009). RuBisCo activase and wheat productivity under heat-stress conditions. J. Exp. Bot. 60, 4003-4014. doi: 10.1093/jxb/erp241

Rokka, A., Zhang, L., and Aro, E. M. (2001). RuBisCo activase: an enzyme with a temperature-dependent dual function? Plant J. 25, 463-471. doi: 10.1046/j.1365-313x.2001.00981.x

Sage, R. F., Way, D. A., and Kubien, D. S. (2008). RuBisCo, RuBisCo activase, and global climate change. J. Exp. Bot. 59, 1581-1595. doi: 10.1093/jxb/ern053

Salvucci, M. E., and Crafts-Brandner, S. J. (2004a). Mechanism for deactivation of RuBisCo under moderate heat stress. Physiol. Plant. 122, 513-519. doi: 10.1111/j.1399-3054.2004.00419.x

Salvucci, M. E., and Crafts-Brandner, S. J. (2004b). Inhibition of photosynthesis by heat stress: the activation state of RuBisCo as a limiting factor in photosynthesis. Physiol. Plant. 120, 179-186. doi: 10.1111/j.0031-9317.2004.0173.x

Salvucci, M. E., and Crafts-Brandner, S. J. (2004c). Relationship between the heat tolerance of photosynthesis and the thermal stability of RuBisCo activase in plants from contrasting thermal environments. Plant Physio. 134, 1460-1470. doi: $10.1104 / p p .103 .038323$

Salvucci, M. E., Osteryoung, K. W., Crafts-Brandner, S. J., and Vierling, E. (2001). Exceptional sensitivity of RuBisCo activase to thermal denaturation in vitro and in vivo. Plant Physiol. 127, 1053-1064. doi: 10.1104/pp.010357

Salvucci, M. E., Portis, A. R., and Ogren, W. L. (1985). A soluble chloroplast protein catalyzes ribulose bisphosphate carboxylase/oxygenase activation in vivo. Photosyn Res. 7, 193-201. doi: 10.1007/BF00037012

Sambrook, J., Fritsch, E. F., and Maniatis, T. (1989). Molecular Cloning. New York, NY: Cold spring harbor laboratory press.

Tcherkez, G., Farquhar, G. D., and Andrews, T. J. (2006). Despite slow catalysis and confused substrate specificity, all ribulose bisphosphate carboxylases may be nearly perfectly optimized. Proc. Natl. Acad. Sci. U.S.A. 103, 7246-7251. doi: 10.1073/pnas.0600605103

To, K. Y., Suen, D. F., and Chen, S. C. G. (1999). Molecular characterization of ribulose-1, 5-bisphosphate carboxylase/oxygenase activase in rice leaves. Planta 209, 66-76. doi: 10.1007/s004250050607

Wahid, A., Gelani, S., Ashraf, M., and Foolad, M. R. (2007). Heat tolerance in plants: an overview. Env. Exp. Bot. 61, 199-223. doi: 10.1016/j.envexpbot.2007.05.011

Wang, D., Li, X. F., Zhou, Z. J., Feng, X. P., Yang, W. J., and Jiang, D. A. (2010). Two RuBisCo activase isoforms may play different roles in photosynthetic heat acclimation in the rice plant. Physiol. Plant. 139, 55-67. doi: 10.1111/j.13993054.2009.01344.x

Wang, G. P., Hui, Z., Li, F., Zhao, M. R., Zhang, J., and Wang, W. (2010). Improvement of heat and drought photosynthetic tolerance in wheat by over-accumulation of glycinebetaine. Plant Biotechnol. Rep. 4, 213-222. doi: 10.1007/s11816-010-0139-y

Yamori, W., Masumoto, C., Fukayama, H., and Makino, A. (2012). RuBisCo activase is a key regulator of non-steady-state photosynthesis at any leaf temperature and, to a lesser extent, of steady-state photosynthesis at high temperature. Plant J. 71, 871-880. doi: 10.1111/j.1365-313X.2012.05041.x

Yin, Z., Zhang, Z., Deng, D., Chao, M., Gao, Q., Wang, Y., et al. (2014). Characterization of RuBisCo activase genes in maize: an $\alpha$-isoform gene functions alongside a $\beta$-isoform gene. Plant Physiol. 164, 2096-2106. doi: $10.1104 /$ pp.113.230854

Zhu, J. K. (2001). Plant salt tolerance. Trends Plant Sci. 6, 66-71. doi: 10.1016/S1360-1385(00)01838-0

Conflict of Interest Statement: The authors declare that the research was conducted in the absence of any commercial or financial relationships that could be construed as a potential conflict of interest.

Copyright (c) 2016 Kumar, Goswami, Singh, Dubey, Singh, Sharma, Verma, Kala, Rai, Grover, Mishra, Singh, Pathak, Chinnusamy, Rai and Praveen. This is an openaccess article distributed under the terms of the Creative Commons Attribution License (CC BY). The use, distribution or reproduction in other forums is permitted, provided the original author(s) or licensor are credited and that the original publication in this journal is cited, in accordance with accepted academic practice. No use, distribution or reproduction is permitted which does not comply with these terms. 